\title{
Inelastic Parametric Analysis of Seismic Responses of Multistorey Bidirectional Eccentric Structure
}

\author{
Yu-ping Kuang $\mathbb{D},{ }^{1,2}$ Xin-liang Jiang, ${ }^{2,3}$ and Nan Jiang $\mathbb{D}^{2,3}$ \\ ${ }^{1}$ School of Civil Engineering and Communication, North China University of Water Resources and Electric Power, \\ Zhengzhou 450045, China \\ ${ }^{2}$ School of Civil Engineering, Tianjin University, Tianjin 300072, China \\ ${ }^{3}$ Key Laboratory of Coast Civil Structure Safety of Ministry of Education, Tianjin University, Tianjin 300072, China
}

Correspondence should be addressed to Yu-ping Kuang; kuangyuping8826@163.com

Received 23 September 2017; Revised 10 February 2018; Accepted 8 May 2018; Published 21 June 2018

Academic Editor: Ivo Caliò

Copyright (C) 2018 Yu-ping Kuang et al. This is an open access article distributed under the Creative Commons Attribution License, which permits unrestricted use, distribution, and reproduction in any medium, provided the original work is properly cited.

\begin{abstract}
This paper conducts a parametric study on the seismic response of multistorey bidirectional eccentric structures from elastic stage to inelastic stage. Based on a simplified multistorey bidirectional eccentric model composed of bidirectional lateral load-resisting members, a general law is proposed for three-stage natural frequency variation behaviour from elastic stage to inelastic stage of eccentric frame structures with different layers. Different simplification treatments are conducted on each stage and the three stable parameter analysis stages are defined. The corresponding dynamic stiffness matrices and motion equations in different loading stages are derived. On this basis, a parametric analysis of seismic response of a three-storey bidirectional regular eccentric structure from elastic stage to inelastic stage is conducted. Effects of the uncoupled torsion to lateral frequency ratios $(\Omega)$ and bidirectional eccentricities on the seismic responses are investigated. The results reveal that as $\Omega$ increases, translational displacement in the load direction first decreases and then increases; meanwhile, the displacement perpendicular to load direction and torsion displacement first rise and then decrease sharply. When $\Omega=1.1$, the coupling effect between the translation in the load direction and the torsion is at its strongest condition. Increasing the eccentricities leads to a decrease in the displacement in the load direction as well as an increase in the displacement perpendicular to load direction and torsion displacement. Variation regularity of inelastic seismic response is remarkably different from that in elastic stage. The lateral-torsional coupling effect of the bidirectional eccentric structure is closely related to both the period ratio and the bidirectional eccentricities.
\end{abstract}

\section{Introduction}

The trends toward developing modern buildings with complex and irregular shapes have led to serious concerns with problems associated with structural irregularities. In these irregular structures having an uneven distribution of mass or stiffness, the centers of resistance do not coincide with the centers of mass. When these structures, so-called eccentric buildings, are subjected to earthquake ground motions, they undergo both translational and rotational motions, even though the earthquake excitation is purely unidirection translational. Observations following seismic events have revealed that these eccentric structures tend to suffer from structural damage more seriously than noneccentric ones because of the influence of lateral-torsional coupling $[1,2]$. The lateral-torsional coupling behaviours of eccentric structures have since attracted continuous attention from scholars and engineers alike, and many research results have been reported [3-6].

The initial research focused on the single-storey eccentric structure. The system parameters of a single-storey, oneway eccentric structure in an elastic earthquake response can be analytically determined. These parameters include the uncoupled torsion to lateral frequency ratio, the stiffness eccentricity of the floor, and the natural period of the structure $[7,8]$. Kan and Chopra [9] conducted the first parametric studies on the inelastic response of single-storey one-way eccentric structure. They declared that the lateral-torsional coupling effect in inelastic stage depends significantly on uncoupled torsion to lateral frequency ratio. The system in 
inelastic stage is more and more close to the translation motion of a system with a single degree of freedom. In contrast to these findings, scholars such as Tso, Sadek, and Bzorgnia [10, 11] reported that eccentric system does not respond primarily translation in inelastic stage. The different or even contradictory conclusions provided by these studies are mainly attributed to the fact that the researchers adopted different analysis models or parameter calculation methods. Kan and Chopra [9] adopted a very simple model that consisted of a single lateral load-resisting member. Meanwhile, studies by Tso and Sdek [10] and Bozorgnia and Tso [11] utilized models consisting of three lateral load-resisting members. Kan and Chopra [9] and Tso and Sadek [10] defined and calculated the uncoupled torsion to lateral frequency ratio $\Omega$ based on a vertical axis around the mass center, while Bozorgnia and Tso [11] selected a vertical axis around the stiffness center. From the above literature, it is known that the study of singlestorey eccentricity structure is more mature. As a result of the comprehensive literature, experts have arrived at a universal conclusion about lateral-torsional coupling in the elastic stage of single-storey eccentric structure. However, the studies of lateral-torsional coupling in the inelastic stage have not always got generally applicable conclusions. And there are more research and discussion on this aspect [12-14].

The seismic responses of multistorey eccentric structures in elastic and inelastic stages are more complex than the responses of single-storey, one-way asymmetrical buildings subjected to earthquake motion. Currently, the available investigations primarily concentrate on the dynamic analysis of these regularly asymmetrical multistorey buildings. Marušić et al. [15] studied the elastic and inelastic seismic response of a multistorey regular eccentric steel frame structure under bidirectional earthquake motions. They found that the reduction in lateral stiffness due to plastic deformations in a certain direction may considerably influence the lateral load-resisting member in the orthogonal direction. Magliulo and Ramasco [16] compared the seismic response of a multistorey one-way eccentric frame structure under the influence of unidirectional and bidirectional earthquakes. Their results indicated that the maximum base shear and the top displacement are not very sensitive to the presence of the orthogonal component, which, conversely, leads to a large increase in the column plastic excursions. Jiang and Kuang [17] investigated the influence of uncoupled torsion to lateral frequency ratio and bidirectional eccentricities on the normalized frequencies of multistorey bidirectional stiffness eccentric structures from elastic stage to inelastic stage. Bosco et al. [18] proposed new corrective eccentricity aiming at generalizing and simplifying the previous corrective eccentricity method, and these equations of corrective eccentricities are defined based on the response of a set of single-storey systems representative of buildings. This research lays the foundation for the application of nonlinear static method in seismic assessment of eccentric structures. Wang [8] took strength eccentricity as the inelastic impact factor and studied the inelastic seismic response of multistorey eccentric structures. They declared that under the influence of earthquakes with different intensities, the maximum displacement ductility requirement mostly occurred in stiff side members, where it was about two to four times the value found in the flexible side members. Scholars including Wu et al. [19] analyzed the seismic responses of asymmetric regular multistorey buildings in both the elastic and inelastic stages. They found that the ductility responses of members at the stiff side increase with the increase of eccentricities. By adopting a 3D plastic hinge model, which closely approximates actual frame structures, Stathopoulos et al. [20] conducted inelastic dynamic time history analysis of multistorey bidirectional eccentric structures. In contrast to related noneccentric systems, the so-called flexible side frames had more ductility requirements than that of stiff side frames; this finding was also different from previous results using the simplified one-storey model [21]. Rizwan et al. [22] utilized the SAP2000 to construct a plastic hinge model of a 3D frame structure and conducted nonlinear dynamic history analysis on two kinds of asymmetric structures. The first kind was a mass symmetric system, with strength, stiffness, and both strength and stiffness eccentricities. The second kind was a mass eccentric system. Rizwan's results indicated that, for the first kind of system, the response can be better corelated to the strength eccentricity. And the second kind of system exhibited almost uniform ductility demand in beams of various frames for smaller eccentricities. Halabian et al. [23] studied mass eccentricity and stiffness eccentricity in terms of the inelastic seismic response of a multistorey bidirectional eccentric frame-shear structure and evaluated the torsion effect using the unified ductility requirement distributed along the structure's height direction. The results demonstrated that, as for a system consisting of dual lateral load-resisting members, column at the corner of the flexible side has greater ductility requirements than that of a similar frame system.

It can be seen that $[8,19,20,22,23]$ drew different conclusions, which can be attributed to the differences among the analytical models, parameter calculation methods, eccentricity types, and input seismic waves adopted in these studies. Reference [19] calculated the approximate floor stiffness eccentricity based on the first order of the stiffness of lateral load-resisting members in each layer. Meanwhile, [20, 22] conducted push-over analysis of each frame and obtained related force-displacement curves. By fitting the results to a second-line model, the elastic lateral load-resisting stiffness of each frame was obtained, and the stiffness eccentricity was calculated. Reference [8] primarily analyzed the influence of mass eccentricity on the inelastic response, while [20, 22, 24] demonstrated that the inelastic response of the mass eccentricity structure differs from that of the stiffness eccentricity structure. Therefore, the findings of [8] require further validation in order to determine if they are applicable to multistorey structures with stiffness eccentricity.

In addition to the dynamic time history analysis, some experts have expanded the parameter analysis, but most of them are confined to the elastic stage. Chopra et al. [7, 25] conducted elastic parametric analysis of the seismic responses of multistorey eccentric structures using the modesuperposition response spectrum method. Their results indicated that the effects of lateral-torsional coupling on the response of a multistorey eccentric building and its associated one-storey system are similar. Duan and Chandler [26, 27] further reported that a single-storey structural model is not 
on its own sufficient to investigate completely the inelastic torsional effects in multistorey regularly asymmetric buildings which are unlike elastic studies. Anagnostopoulos et al. [28] pointed out that conclusions based on the widely used simplified, one story, eccentric systems of the shear-beam type, to actual, nonsymmetric buildings and consequent assessments of the pertinent code provisions, can be quite erroneous, unless special care is taken to match the basic properties of the simplified models to those of the real buildings. It can been seen that the lateral-torsional coupling behaviour is well understood within the limits of elastic deformations but is still far from being fully understood in inelastic stage even for a special multistorey regular eccentric structure. Studies show that the lateral-torsional coupling behaviour in inelastic stage is obviously different from that in elastic stage [17]. After entering the inelastic stage, the lateral load-resisting members experience buckling, unloading, and reverse loading under the influence of earthquake motion. Under these circumstances, the locations of stiffness centers continue to move, and the stiffness center of each layer no longer remains in the same vertical axis direction, creating difficulties for investigation and analysis. Therefore, the multistorey eccentric model should be adopted in the inelastic parameter analysis so as to obtain some regular conclusions.

A thorough review of the literature summarized above leads to the conclusion that no consensus has been reached concerning the inelastic behaviours of multistorey eccentric structures. Only by conducting systematic parametric analysis can we obtain the variation regularity of seismic response in the inelastic stage. The primary aim of this paper is to present a systematic parametric study on the variation of lateral-torsional coupling behaviour of multistorey bidirectional eccentric structure, thereby providing a basis for intensive studies leading to their effective improvement on other aspects. Therefore, based on the proposed multistorey eccentric simplified model composed of bidirectional lateral load-resisting members, this paper outlines a general law for the three-stage natural frequency variation behaviour from elastic to inelastic stage of eccentric structures with different layers. Different simplification treatments are conducted in these three stages; accordingly, three stable parameter analysis stages are defined, and the motion equations of different stages are deduced. The structural seismic response of each stage is gained by solving the motion equation in each stage. On this basis, parametric analyses on seismic responses of multistorey bidirectional regular eccentric structures are conducted from elastic to inelastic stage. Influences of uncoupled torsion to lateral frequency ratios and bidirectional eccentricities on the structural seismic response are investigated, and a general law of seismic response is obtained, changing with different parameters in all three stages. Finally, the variation regularity of torsion-translation displacement ratio with the period ratio under different eccentricities is discussed. The results can provide references for the design and earthquakeproofing of relevant structures.

\section{Analytical Model and Motion Equation}

2.1. Establishment of the Eccentric Simplified Model. A reinforced concrete bidirectional eccentric frame structure with

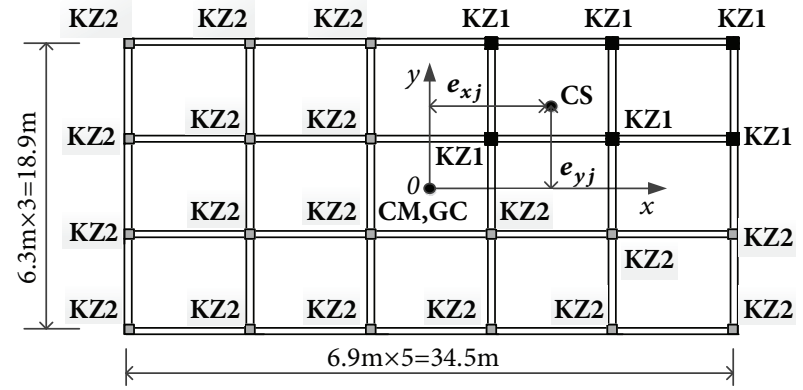

FIGURE 1: Plan view of structure investigated.

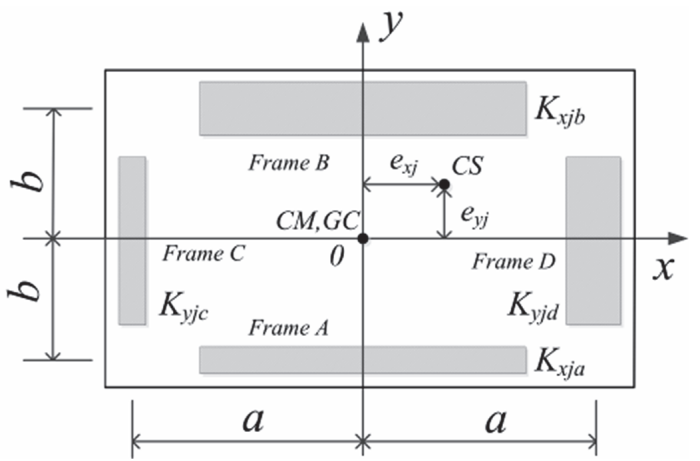

FIGURE 2: Plan view of the simplified model.

$p \times q$ spans and $N$-storey is illustrated in Figure 1. Only the stiffness eccentricities caused by the irregular planar distribution of columns are considered in this example, and no changes are presented along the vertical direction of the columns; in other words, the structure investigated herein is a regular eccentric structure. $C M$ and $G C$ stand for the mass center and geometric center of each layer, respectively; $C S$ stands for the stiffness center, with a coordinate of $\left(e_{x j}, e_{y j}\right)$. A spatial shear-torsional type series rigid plate layer model with bidirectional lateral load-resisting members is introduced in order to conveniently conduct parametric analysis of structural models with different uncoupled torsion to lateral frequency ratios or stiffness eccentricities. The assumptions of this model, shown in Figure 2, are as follows:

(1) The mass center $(C M)$ of each floor distributes in one line and is located at the geometric center $(G C)$ of the slab. The radius of gyration of the mass center of each floor is the same.

(2) The masses of slab and columns of each floor are concentrated at the mass center of that floor.

(3) The degrees of freedom of each floor are located at the mass center of the slab. Each floor has three degrees of freedom: translation degrees of freedom in the $x$ and $y$ directions as well as a torsion degree of freedom around the vertical axis.

(4) The slab is rigid within its plane, and the out-of-plane stiffness is small and can be ignored. 
(5) Out-of-plane stiffness and torsional inertia of each lateral load-resisting member are assumed to be negligible and thus ignored in the analysis.

The slab for each floor is supported by four massless, axially inextensible load-resisting members: frame $A$, frame $\mathrm{B}$, frame $\mathrm{C}$, and frame $\mathrm{D}$. By combining the frame in the $x$ direction of the $j$ th floor of the original structure to double sides, frames A and B are formed, which provide lateral stiffness in the $x$ direction. Similarly, by combining the frame in the $y$ direction of the $j$ th floor of the original structure to double sides, frames $\mathrm{C}$ and $\mathrm{D}$ are formed, which provide lateral stiffness in the $y$ direction. Frame A and frame B are located at equal distance $b$ from, but on opposite sides of, $x$-axis; frame $\mathrm{C}$ and frame D are located at equal distance $a$ from, but on opposite sides of, $y$-axis. Compared to the $j$ th floor of the original model, the $j$ th floor of the simplified model has the same total lateral stiffness on the horizontal axis, the same torsion stiffness about the mass center, and equal bidirectional eccentricities. The calculation formulas of the simplified model are listed as (1)-(3). The simultaneous solution of six formulas in (1)-(3) yields the parameters of the simplified model, which are listed in (4)-(6).

$$
\begin{aligned}
& K_{x j b}+K_{x j a}=K_{x j} \\
& K_{y j d}+K_{y j c}=K_{y j} \\
& K_{x j b} \times b^{2}+K_{x j a} \times b^{2}=\sum k_{x j i} \times y_{j i}^{2}, \\
& K_{y j d} \times a^{2}+K_{y j c} \times a^{2}=\sum k_{y j i} \times x_{j i}{ }^{2} \\
& \frac{K_{x j b} \times b+K_{x j a} \times(-b)}{K_{x j b}+K_{x j a}}=e_{y j}, \\
& \frac{K_{y j d} \times a+K_{y j c} \times(-a)}{K_{y j d}+K_{y j c}}=e_{x j} \\
& a=\sqrt{\frac{\sum k_{y j i} \times x_{j i}^{2}}{K_{y j}}}, \\
& b=\sqrt{\frac{\sum k_{x j i} \times y_{j i}^{2}}{K_{x j}}} \\
& K_{x j b}=\frac{K_{x j}}{2}\left(1+e_{y j} \sqrt{\frac{K_{x j}}{\sum k_{x j i} \times y_{j i}^{2}}}\right) \text {, } \\
& K_{x j a}=\frac{K_{x j}}{2}\left(1-e_{y j} \sqrt{\frac{K_{x j}}{\sum k_{x j i} \times y_{j i}^{2}}}\right) \\
& K_{y j d}=\frac{K_{y j}}{2}\left(1+e_{x j} \sqrt{\frac{K_{y j}}{\sum k_{y j i} \times x_{j i}^{2}}}\right) \text {, } \\
& K_{y j c}=\frac{K_{y j}}{2}\left(1-e_{x j} \sqrt{\frac{K_{y j}}{\sum k_{y j i} \times x_{j i}^{2}}}\right)
\end{aligned}
$$

where $k_{x j i}$ and $k_{y j i}$ denote the lateral stiffness of the $i$ th column of floor $j$ in the $x$ and $y$ directions, respectively; $x_{j i}$ and $y_{j i}$ are, respectively, the $x$ and $y$ coordinates of the $i$ th column of floor $j ; K_{x j}=\sum k_{x j i}$ and $K_{y j}=\sum k_{y j i}$ represent the total translational stiffness of floor $j$ in the $x$ and $y$ directions, respectively; $K_{\theta j}=\sum k_{x j i} \times y_{j i}{ }^{2}+\sum k_{y j i} \times x_{j i}{ }^{2}$ denotes the torsional stiffness about the mass center of floor $j ; e_{x j}$ and $e_{y j}$ designate the $x$ and $y$ coordinates of the stiffness center $(C S)$ of floor $j$. As in multistorey buildings, the center of rigidity cannot be exactly defined, an approximate $C S$ of floor $j$ is computed herein for reference purposes, $e_{x j}=\sum k_{y j i} x_{j i} /$ $K_{y j}, e_{y j}=\sum k_{x j i} y_{j i} / K_{x j}$ [23]. The normalized stiffness eccentricities of floor $j$ are defined as $b_{x j}=e_{x j} / r_{j}, b_{y j}=e_{y j} / r_{j} ; r_{j}$ is the radius of gyration of the mass center of floor $j . K_{x j b}, K_{x j a}$, $K_{y j d}$, and $K_{y j c}$ are the lateral stiffness of each frame in the $j$ th floor of the simplified model.

It can be seen from (1)-(2) that $k_{x j i}$ and $k_{y j i}$ of floor $j$ of the original model are kept constant in the elastic stage; thus, $K_{x j}$ and $K_{y j}$ also remain constant. Consequently, $b$ and $a$ of floor $j$ of the simplified model do not vary. When the structure enters the inelastic stage, $k_{x j i}$ and $k_{y j i}$ vary with the load, and correspondently, $b$ and $a$ will also vary. It is suggested that when conducting inelastic analysis by adopting a simplified model in replace of the original structure, the values of $b$ and $a$ can be adjusted so that the simplified model can be used to accurately replace the original model for inelastic analysis.

2.2. Solving the Motion Equation. The stiffness matrix of an $N$-storey bidirectional eccentric structure can be acquired based on the direction stiffness method [29], which also allows its motion equation to be deduced. Take a three-storey bidirectional eccentric structure serving as an example, the motion equation under an earthquake ground motion in the $x$ direction can be expressed as

$$
\begin{aligned}
& {\left[\mathbf{M}_{s}\right]\{\ddot{\boldsymbol{\delta}}(t)\}+\left[\mathbf{C}_{s}\right]\{\dot{\boldsymbol{\delta}}(t)\}+\left[\mathbf{K}_{s}\right]\{\boldsymbol{\delta}(t)\}} \\
& =-\left[\mathbf{M}_{s}\right] \mathbf{l}_{1} \ddot{x}_{g}(t)
\end{aligned}
$$

where $\left[\mathbf{M}_{s}\right],\left[\mathbf{K}_{s}\right],\{\boldsymbol{\delta}(t)\}$, and $\mathbf{l}_{1}$ are the mass matrix, stiffness matrix, displacement matrix, and transformation matrix, respectively, as described in [22]. The damping matrix $\left[\mathbf{C}_{s}\right]$ and $\left[\mathbf{K}_{s}\right]$ share the same modality. That is to say, $\left[\mathbf{C}_{s}\right]$ is assumed to be proportional to the stiffness matrix $\left[\mathbf{K}_{s}\right]$. It is defined by

$$
\left[\mathbf{C}_{s}\right]=\beta\left[\mathbf{K}_{s}\right]
$$

in which $\beta=2 \zeta / \omega_{1}, \omega_{1}$ is the first natural angular frequency, and $\zeta$ is the corresponding damping ratio. According to the provisions by Code for Seismic Design of Building [30], $\zeta$ is advisable to 0.05 .

Equation (7) is a differential equation in the time domain, and its calculation process is tedious. Therefore, it is necessary to transform it into a linear equation in complex frequency domain. $U_{s}(\omega)$ is defined as the Fourier transformation of the displacement $\{\delta(t)\}$. Thus, the Fourier transform is applied to (7), and the following results can be obtained: 


$$
\begin{aligned}
- & \omega^{2}\left[\mathbf{M}_{s}\right] \mathbf{U}_{s}(\omega)+\left[\mathbf{K}_{s}\right] \mathbf{U}_{s}(\omega)+i \omega\left[\mathbf{C}_{s}\right] \mathbf{U}_{s}(\omega) \\
& =\omega^{2}\left[\mathbf{M}_{s}\right] \mathbf{l}_{1} X_{g}(\omega)
\end{aligned}
$$

Equation (9) can be solved using the modal analysis method. However, because there are nine degrees of freedom, the solution cannot be explicitly expressed. Therefore, software programming is required to calculate the natural frequency and related vibration mode $\Phi$ via numerical method. By expanding the structural seismic response in complex frequency domain with its inherent vibration mode as the base, there is

$$
\mathbf{U}_{s}(\omega)=\Phi \mathbf{Z}(\omega)
$$

where $\mathbf{Z}(\omega)=\left\{Z_{k}\right\}$ is the column vector of modal displacements of structure and $Z_{k}$ is the modal displacement of $k$ th modal.

Assuming that a structure on a rigid foundation possesses classical normal modes, its natural frequency and vibration mode satisfy the following orthogonality conditions [31]:

$$
\begin{aligned}
& \boldsymbol{\Phi}^{\mathrm{T}}\left[\mathbf{M}_{s}\right] \boldsymbol{\Phi}=\mathrm{I}, \\
& \boldsymbol{\Phi}^{\mathrm{T}}\left[\mathbf{K}_{s}\right] \boldsymbol{\Phi}=\operatorname{diag}\left[\omega_{k}^{2}\right], \\
& \boldsymbol{\Phi}^{\mathrm{T}}\left[\mathbf{C}_{s}\right] \boldsymbol{\Phi}=\operatorname{diag}\left[2 \zeta_{k} \omega_{k}\right]
\end{aligned}
$$

where I is $\mathrm{N} x \mathrm{~N}$ identity matrix, $\omega_{k}$ and $\xi_{k}$ are, respectively, the natural frequency of $k$ th mode and the damping ratio of $k$ th mode, and diag[•] denotes a diagonal matrix.

Introducing the transformation of (10) and applying the orthogonality conditions (9), when premultiplied by $\boldsymbol{\Phi}^{\mathrm{T}}$, become

$$
\begin{gathered}
\operatorname{diag}\left[-\omega^{2}+i 2 \omega \xi_{k} \omega_{k}+\omega_{k}^{2}\right] \mathbf{Z}(\omega) \\
=\omega^{2} \boldsymbol{\Phi}^{\mathrm{T}}\left[\mathbf{M}_{s}\right] \mathbf{1}_{1} X_{g}(\omega)
\end{gathered}
$$

Defining the modal structure transfer function $\mathbf{H}(\omega)$

$$
\begin{aligned}
\mathbf{H}(\omega) & =\operatorname{diag}\left[H_{k}(\omega)\right] \\
H_{k}(\omega) & =-\frac{1}{\omega_{k}^{2}-\omega^{2}+i 2 \omega \xi_{k} \omega_{k}}
\end{aligned}
$$

$\mathbf{H}(\omega)$ is also called the complex frequency response function. The modal displacement can be obtained from (12).

$$
\mathbf{Z}(\omega)=-\omega^{2} \mathbf{H}(\omega) \boldsymbol{\Phi}^{\mathrm{T}}\left[\mathbf{M}_{s}\right] \mathbf{l}_{1} X_{g}(\omega)
$$

Substituting (15) into (10), the structural seismic response in complex frequency domain can be obtained.

$$
\mathbf{U}_{s}(\varpi)=\Phi \mathbf{Z}(\omega)=-\varpi^{2} \Phi \mathbf{H}(\omega) \Phi^{T}\left[\mathbf{M}_{s}\right] \mathbf{l}_{1} X_{g}(\omega)
$$

The ratio of the displacements in complex frequency domain at the mass center of each floor to Fourier transform of the ground motion displacement, denoted as $\left|\mathbf{U}_{s}(\omega)\right| /$ $\left|X_{g}(\omega)\right|$, is referred to as the displacement transfer function. And $\left|\mathbf{U}_{s}(\omega)\right| /\left|X_{g}(\omega)\right|$ is a physical parameter representing its own characteristics and only related to the frequency of earthquake motion $\omega$, regardless of the type of earthquake motion. As the ratio $\left|\mathbf{U}_{s}(\omega)\right| /\left|X_{g}(\omega)\right|$ reflects the dynamic response of the system under unit harmonic excitation, the transfer function can represent the structural dynamic response when given the same input. The interstory displacement is defined as follows:

$$
\begin{aligned}
& \Delta U_{s x j}(\Phi)=U_{s x j}(\omega)-U_{s x(j-1)}(\omega), \\
& \Delta U_{s y j}(\Phi)=U_{s y j}(\omega)-U_{s y(j-1)}(\omega), \\
& \Delta U_{s \theta j}(\omega)=U_{s \theta j}(\omega)-U_{s \theta(j-1)}(\omega)
\end{aligned}
$$

$\left|\Delta U_{s x j}(\omega)\right| /\left|X_{g}(\omega)\right|$ and $\left|\Delta U_{s y j}(\omega)\right| /\left|X_{g}(\omega)\right|$ are, respectively, the interstory translation displacement transfer functions in the $x$ and $y$ directions of floor $j ;\left(r\left|\Delta U_{s \theta j}(\omega)\right| /\right.$ $\left.\left|X_{g}(\omega)\right|\right)_{\max }$ is the interstory torsion displacement transfer function of floor $j$.

\section{Analysis Methods}

3.1. Natural Frequency Analysis of Multistorey Eccentric Frame Structures. This analysis takes a typical $5 \times 3$ spans threestorey bidirectional regular eccentric frame structure with spans of $6.9 \mathrm{~m}$ and $6.3 \mathrm{~m}$ as an example. Its plane layout is shown in Figure 1. And its layer height is $3.9 \mathrm{~m}$. The columns in Figure 1 marked as KZ1 have dimensions of $0.5 \mathrm{~m} \times 0.55 \mathrm{~m}$ $\left(b_{x} \times h_{y}\right.$, similarly hereinafter), with a total column number of 6 . The remaining frame columns marked as KZ2 have dimensions of $0.40 \mathrm{~m} \times 0.45 \mathrm{~m}$, with a total column number of 18. The cross-sections of the longitudinal beams are 0.25 $\mathrm{m} \times 0.6 \mathrm{~m}$, the cross-sections of the transverse beams are $0.25 \mathrm{~m} \times 0.55 \mathrm{~m}$, and the dimensions of the secondary beams are $0.2 \mathrm{~m} \times 0.4 \mathrm{~m}$. The thickness of the floor slab is $0.1 \mathrm{~m}$. The concrete strength of the floor, beam, and column is C30. Moreover, there is no variation in each column along the vertical direction. That is, the structure investigated herein is a regular eccentric structure. Applying the method described in Section 2.1 yields the simplified model of the eccentric frame structure. In order to carry out the full-process analysis from elastic to inelastic stage, the original structure is treated as a shear frame structure, and the corresponding column is considered to be a member with shear deformation as the main part. That is to say, the restoring force model used in this article is based on the member. The force-displacement relationship of each lateral load-resisting member-both in the $x$ and $y$ directions of the original and simplified models is simulated by the bilinear hysteretic model as shown in Figure 3. $K_{1}$ denotes the stiffness of the member in the elastic stage; $K_{2}$ designates the stiffness after yielding, taken as $10 \%$ of the elastic stiffness, and it is tangent stiffness [32]; and $\Delta_{y}$ is the yield displacement, which can be calculated according to empirical equations [33].

The nonlinear static analyses are, respectively, carried out on the original three-storey bidirectional eccentric model and corresponding simplified model. Through gradual loading, inverted triangle static loads in the $x$ direction are applied on the mass centers of each floor. Nonlinear problems are settled based on the load increment method. The eccentricities and 


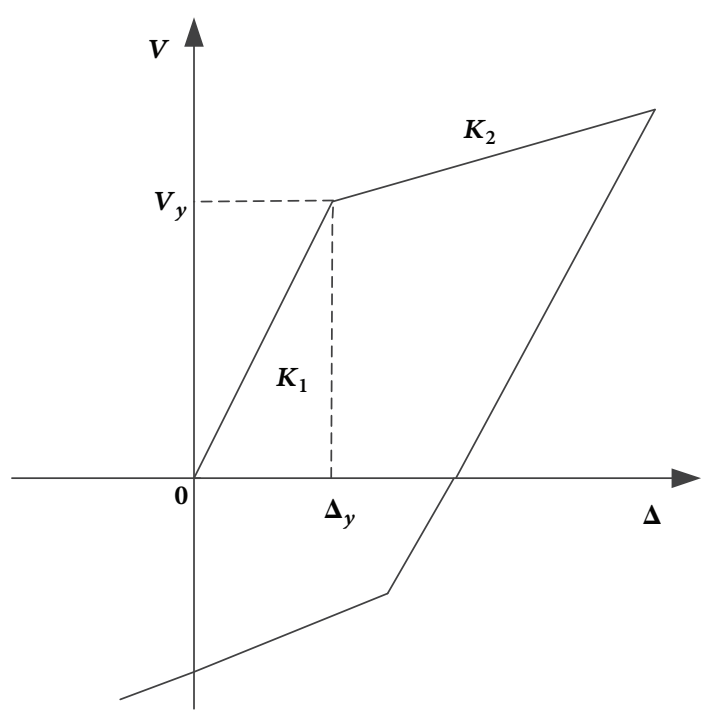

FIGURE 3: Bilinear restoring force model for each lateral load-resisting member.

the displacement of each floor are calculated at each step. Then, the displacement of each member is calculated according to its coordinate position. Next, the stiffness of each member is also modified according to the its displacement and related restoring force model at each step in order to form a new stiffness matrix for the next step analysis. Therefore, the nonsynchronization of the displacements of the members, which is induced by the torsion of the floor, can be considered in detail during analysis. When the story drift angle $\theta_{p}$ of a certain layer reaches $1 / 50$ of the inelastic story drift angle limit of frame structures dictated in the Code for Seismic Design of Building [30], loading is stopped. The entire analysis process is achieved by $\mathrm{M}$ language programming in MATLAB.

The normalized stiffness eccentricities $b_{x 1}$ and $b_{y 1}$ of the original model and the corresponding simplified model are evaluated in Figure 4, where the loading coefficient $\alpha$ of the horizontal axis is defined as the proportion of the applied load to the entire final load on the structure, with a maximum value of 1 . It can be noted from Figure 4 that the variation curve of $b_{x 1}$ with $\alpha$ has no mutation points, indicating that the members perpendicular to the load direction on the first floor do not yield. Conversely, mutation points appear on the variation curve of $b_{y 1}$ with $\alpha$, suggesting that the members in the load direction on the first floor gradually yield. Variations of $b_{y 2}$ and $b_{x 2}$ are respectively similar to those of the first floor. Moreover, $b_{y_{3}}$ and $b_{x 3}$ remain straight lines with $\alpha$, which indicate that all the members on the third floor do not yield. It also can be seen from Figure 4 that, during the entire loading process, variation of $b_{y 1}$ of the simplified model matches favorably with that of the original model. Only during the yielding process of some members, there are some differences between the original model and the corresponding simplified model. For the overall analysis of lateral-torsional coupling behaviour of the eccentric structure in this paper, the impact of this difference is within the acceptance of engineering applications.

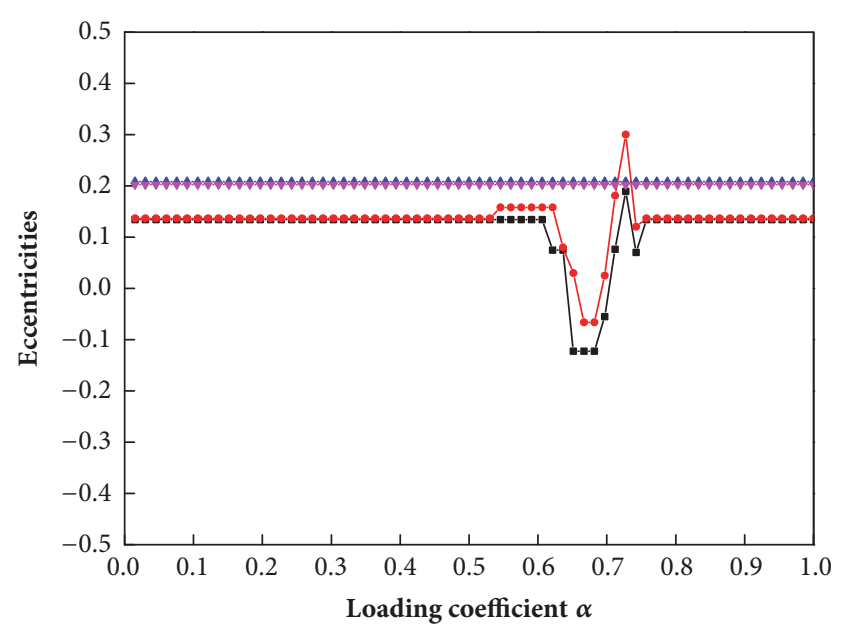

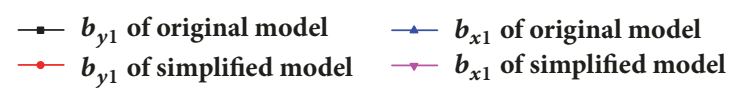

FIGURE 4: Variation of $b_{x 1}$ and $b_{y 1}$ with $\alpha$.

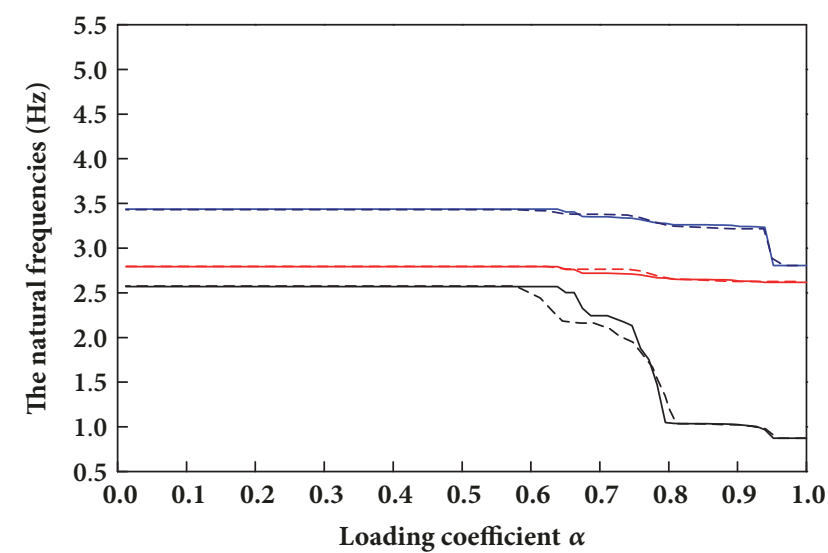

- $f_{1}$ of original model $\quad---f_{1}$ of simplified model

- $f_{2}$ of original model $\quad---f_{2}$ of simplified model

- $f_{3}$ of original model $\quad---f_{3}$ of simplified model

FIGURE 5: Variation of the natural frequencies of the three-storey eccentric structure with $\alpha$.

The first-order natural frequencies of the two models are illustrated in Figure 5. As shown in Figure 5, the firstorder natural frequency of the eccentric frame decreases from $2.569 \mathrm{~Hz}$ to $0.873 \mathrm{~Hz}$. At the same time, the second- and third-order natural frequencies also experience reductions in amplitude smaller than that of the first-order natural frequency. Throughout the entire loading process, the first three natural frequencies of the two models agree well with each other; the elastic stages of the first-order frequency of the two models have a difference of $0.20 \%$, while the maximum deviation in the inelastic stage is $8.25 \%$. These results indicate that, in the elastic stage, the simplified model can effectively fill the role of the original model during analysis. As for the inelastic stage, there are only minor differences during the yielding process of some lateral load-resisting members, but 
the deviation is still acceptable for engineering. The stable variation of the natural frequencies reflects stable variation of the structural integral stiffness, which indicates that the structural stiffness changes of the two models are consistent in the process from elastic to inelastic stage. Therefore, the proposed simplified model is also suitable for analysis in the inelastic stage, and it can reliably replace the original model for full-process parameter analysis.

It can be noted from Figure 5 that the natural frequency reduces gradually through the whole process from elastic to inelastic stage, with the variation occurring in three obvious stages. The first stage takes the form of a horizontal straight line, the second stage is a huge reduction segment like a diagonal line, and the third stage is an approximately horizontal segment with relatively small variation amplitude. When the loading coefficient is larger than 0.92 , the structure is close to sustaining severe damage; therefore, the analysis does not consider this stage. To further validate the variation tendency of the natural frequency of multistorey eccentric frame structures, typical five- and seven-storey structures are selected to analyze vibration regularity. The planar layouts of five- and seven-storey regular eccentric frame structures are similar to that displayed in Figure 1, with a floor height of 3.9 $\mathrm{m}$. The cross-section dimensions of the large columns (KZ1 frame columns) of five-storey eccentric frame structure are $0.60 \mathrm{~m} \times 0.65 \mathrm{~m}$, while those of the small columns (KZ2 frame columns) are $0.50 \mathrm{~m} \times 0.55 \mathrm{~m}$. The cross-section dimensions of the large and small columns of seven-storey eccentric frame structure are $0.65 \mathrm{~m} \times 0.70 \mathrm{~m}$ and $0.55 \mathrm{~m} \times 0.60 \mathrm{~m}$, respectively. The simplified models of eccentric frame structures with five and seven layers can be obtained according to the method described in Section 2.1. The force-displacement relationship of each member of the original and simplified models of the five- or seven-storey structures is also described by the bilinear hysteretic model shown in Figure 3. The corresponding parameters $\left(K_{1}, K_{2}\right.$, and $\left.\Delta_{y}\right)$ are calculated by the same method as the three-storey model. Full-process nonlinear static analyses can then be conducted with these two models. The variation curves of the first-order natural frequencies are shown in Figures 6 and 7.

A comparison of Figures 5, 6, and 7 indicates that the frequency variation regularities of five- and seven-storey eccentric frame structures is similar to that of the three-storey eccentric frame structure; that is, all of the curves are characterized by three different stages. Although the three-, five-, and seven-storey eccentric structures have the same structure plane, their cross-sections of the members are different. The corresponding elastic lateral stiffness and yielding displacement values also differ from each other, as do the initial bidirectional eccentricities and uncoupled torsion to lateral frequency ratios. That is to say, the three examples analyzed above represent common multistorey frame structures, and the three-stage variation regularity represents the general law of multistorey eccentric frame structures. This finding agrees with the frequency variation regularity obtained in other types of analysis [34].

The frequency variation amplitude is largest in the second stage, during which time it also has its maximum influence on the structure. This indicates that the second stage is the

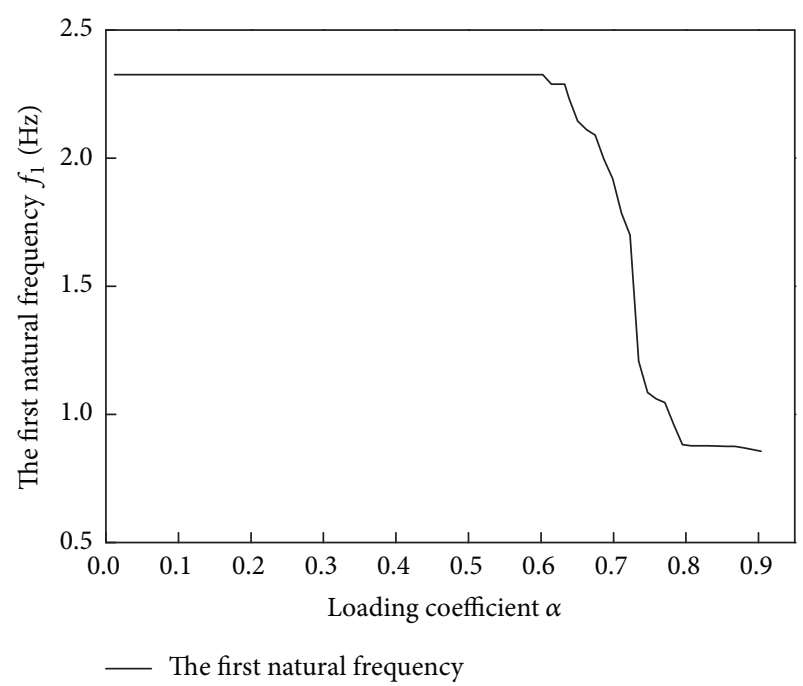

FIGURE 6: Variation of $f_{1}$ of the five-storey eccentric structure with $\alpha$.

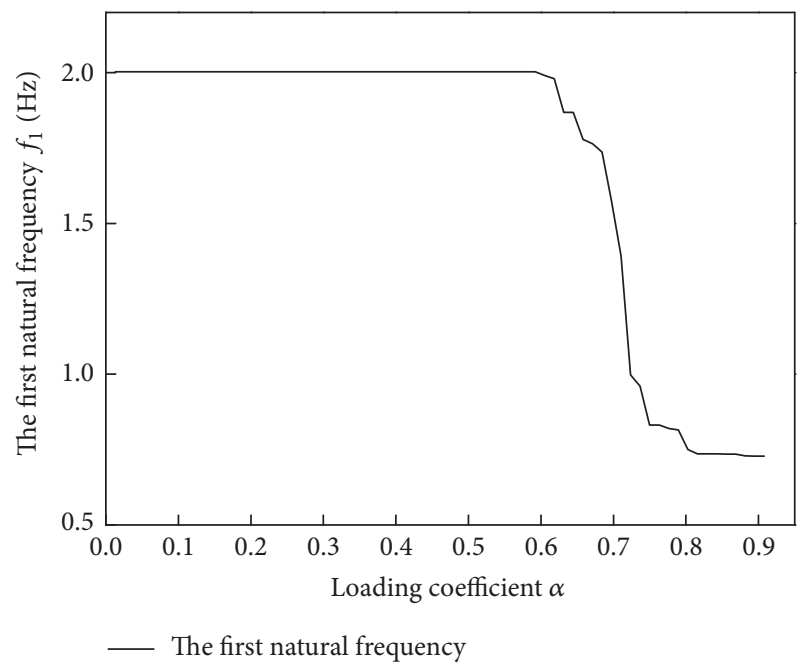

FIGURE 7: Variation of $f_{1}$ of the seven-storey eccentric structure with $\alpha$.

most important component for analysis. According to the second stage variation tendency of the natural frequency in different layers, the frequency during this stage is fitted into a slant line with a linear relationship to the loading coefficient via the least-squares method, making the analysis procedure more convenient. In the third stage, the frequency variation amplitude is very small. During analysis, the average frequency value can be selected for the third stage to simplify the calculation process. The general form of the three-stage frequency can be expressed by

$$
\begin{aligned}
& f_{1-1}=f_{e} \\
& f_{1-2}=k \alpha+s \\
& f_{1-3}=f_{e 3}
\end{aligned}
$$




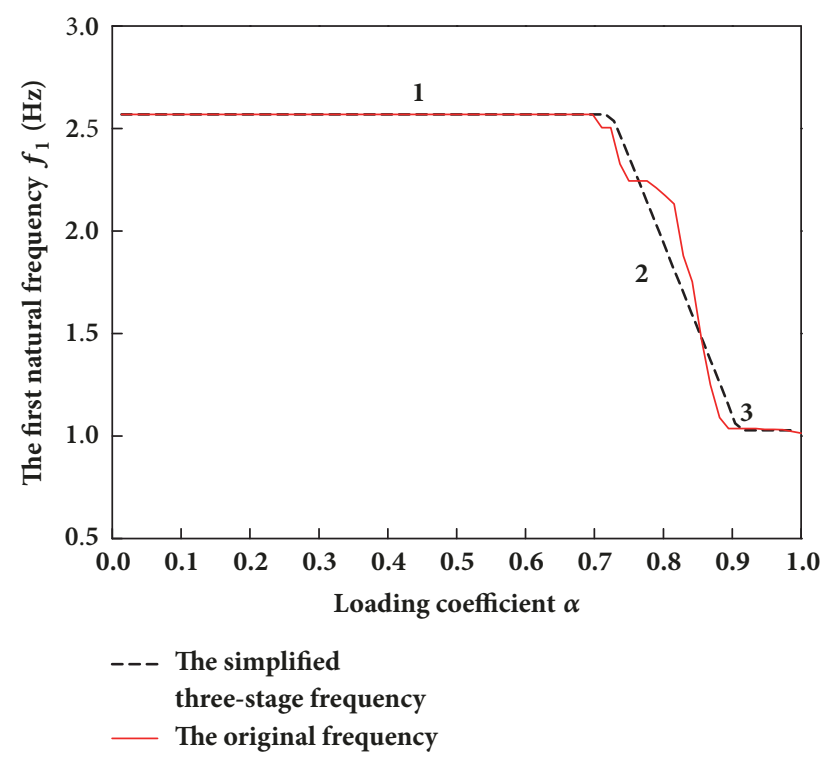

FIGURE 8: Comparison of the simplified three-stage frequency and original frequency of the three-storey eccentric frame structure.

where $f_{e}$ is the first-order natural frequency in the elastic stage of the structure; $k$ and $s$ are, respectively, the monomial coefficient and constant term of the linear variation of frequency in the second stage; and $f_{e 3}$ is the third stage frequency, with its value is equal to the average frequency of this stage. The specific values of the first-order frequency in three stages for the three-storey eccentric frame structure are given in

$$
\begin{aligned}
& f_{31-1}=2.569(\mathrm{~Hz}) \quad(\alpha \leq 0.664) \\
& f_{31-2}=-9.134 \alpha+8.633(\mathrm{~Hz}) \quad(0.664<\alpha \leq 0.833) \\
& f_{31-3}=1.028(\mathrm{~Hz}) \quad(0.833<\alpha \leq 0.916)
\end{aligned}
$$

in which $f_{31-1}, f_{31-2}$, and $f_{31-3}$ are, respectively, the values of the simplified three-stage of the first-order natural frequency. Figure 8 illustrates the variation curves of the simplified threestage frequency and the original frequency.

Similar methods can be adopted to obtain corresponding simplified three-stage frequencies for frame structures with other numbers of layers.

3.2. Description of the Full-Process Three-Stage Analysis. Starting from the three-stage variation features of the natural frequency, three stable parametric analysis stages are defined as the first, second, and third stage. Using the first-order frequency curve in Figure 8 as an example, any one point in the first and third stages can represent the state of the entire segment. Meanwhile, because the second stage is a slant line, selecting any one point as a representative allows the rest of the points to be obtained based on the linear relationship. It can be noted that the structure is in elastic during the first stage parametric analysis, without any lateral load-resisting member yielding. During the second stage, the lateral loadresisting members on the first floor yield gradually along the load direction. For different values of $\alpha$, the related frequency and the total lateral stiffness of the first floor are also different, implying different degrees of inelasticity development in this stage. In the second stage, a point near the center is selected for representativeness. In the third stage, members on the first floor all yield along the load direction, while those on the second floor yield gradually. At the same time, the lateral load-resisting members on the third floor remain elastic. Through the above analysis, we can know that the variation curves of $b_{x 1}, b_{x 2}$, and $b_{x 3}$ with $\alpha$ all stay straights. It shows that, under the load in the $x$ direction, all the members perpendicular to the load direction of the system studied in this article are still in the elastic stage when the loads are limited by $\theta_{p}=1 / 50$. Hence, in order to carry out the fullprocess parametric analysis, the following analyses only consider the elastic stage of the members perpendicular to the load direction. The story stiffness of each floor in each stage together with other parameters of the entire system in that stage is substituted into the stiffness matrix so as to determine the stiffness matrix in each stage. The motion equation of each stage can also be acquired by substituting the stiffness matrix into (7). The motion equation of each stage can be solved by (9)-(16) and parametric analysis of each stage can be conducted.

\section{Parametric Analyses of the Structural Seismic Responses}

Scholars pay special attention to the amplitude of interstory displacement of multistorey eccentric structures, and the interstory displacement can determine the deformation distribution of each floor. Therefore, the peak values of the interstory translational displacement transfer functions in the $x$ and $y$ directions, that is, $\left(\left|\Delta U_{s x j}(\omega)\right| /\left|X_{g}(\omega)\right|\right)_{\max }$ and $\left(\left|\Delta U_{s y j}(\omega)\right| /\left|X_{g}(\omega)\right|\right)_{\max }$, are studied. And the peak value of the interstory torsion displacement transfer function $\left(r\left|\Delta U_{s \theta j}(\omega)\right| /\left|X_{g}(\omega)\right|\right)_{\max }$ is also investigated. This section discusses the variation regularity of these peak values with uncoupled torsion to lateral frequency ratios and bidirectional eccentricities. For the convenience of discussion, the peak value of the displacement transfer function is called "displacement." Here, $\Omega$ is defined as the ratio of the first-order pure torsional frequency to the first-order pure translational frequency in the $x$ direction of the corresponding symmetric system. For a certain $b_{y}$ and $b_{x}$, different ratios $\Omega$ can be generated by adjusting the distribution of the lateral loadresisting members in the $y$ direction and the value of $a$. At the same time, the distribution of the lateral load-resisting elements in the $x$ direction and the total lateral stiffness are kept as constant. That is to say, a set of $\Omega$ can be generated by changing $K_{y j c}, K_{y j d}$, and $a$. Meanwhile, $K_{x j a}, K_{x j b}, b, b_{x}$, and $b_{y}$ and the sum of $K_{y j c}$ and $K_{y j d}$ are kept invariant. There are nine degrees of freedom for the three-storey bidirectional eccentric simplified model analyzed in this paper, and the explicit solution cannot be given directly when $\Omega$ is adjusted. Therefore, it is necessary to use the numerical calculation method of developed MATLAB program. With MATLAB's $\mathrm{M}$ program language, the corresponding $K_{y j c}, K_{y j d}$, and $a$ 

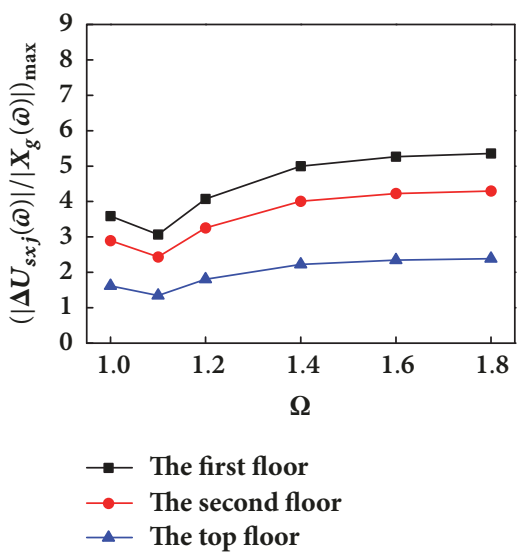

(a) The first stage

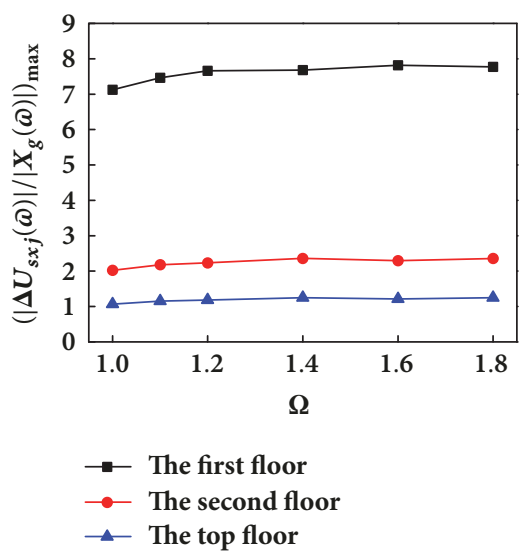

(b) The second stage

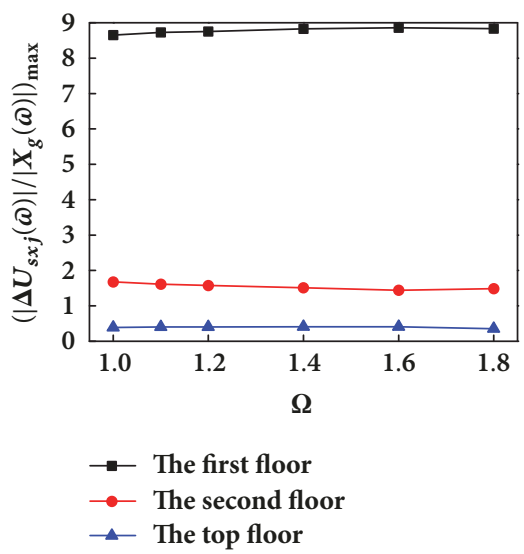

(c) The third stage

FIGURE 9: Interstory translation displacement in the $x$ direction under different $\Omega$ values.

can be easily obtained when some other parameters are kept constant. Then, the value of $\Omega$ of the symmetric system corresponding to the eccentric model can be obtained by using the "eig" function trial calculation in MATLAB. The corresponding parameters are constantly adjusted according to this method until the desired value of $\Omega$ is transferred. The simplified models with different values of $b_{y}$ and $b_{x}$ can be established by adopting the approach specified in study [17]. The range of $\Omega$ is 1.0 to 1.8 , and the range of $b_{y}$ and $b_{x}$ is 0.1 to $0.4[35]$.

4.1. The Effect of $\Omega$ on Interstory Displacement. Variations of interstory translation displacements in the $x$ direction with $\Omega$ from the first to the second and then to the third stage are analyzed in Figure 9. It is evident from Figure 9(a) that the interstory translation displacement in the $x$ direction decreases firstly and then increases with the adding of $\Omega$ in the first stage. The turning point is at $\Omega=1.1$. When $\Omega$ is greater than 1.4 , the increase amplitude is only $1.71 \%$ to $5.33 \%$, tending to stable. Massive calculations reveal that, within the range of 1.0 to $1.4, \Omega$ plays the dominant role in the translation displacement along the $x$ direction when $b_{x}$ is less than or equal to 0.2 . When $b_{x}$ is greater than 0.2 , the key range of $\Omega$ is between 1 and 1.6. Compared to the first stage, the second and third stages (Figures 9(b) and 9(c)) see smaller magnitudes of changes in the translational displacements, and the variation of the interstory translation displacement in the $x$ direction with $\Omega$ is no longer consistent. The influence of $\Omega$ on the translation displacement is reduced by the indepth development of structural inelasticity, and the variation tendencies of displacements of each floor with $\Omega$ are also affected to a certain degree.

The effects of $\Omega$ on the interstory translation displacement in the $y$ direction and the torsion displacement in different stages are, respectively, expressed in Figures 10 and 11. As Figures 10(a) and 11(a) imply, the translation displacement in the $y$ direction and the torsion displacement increase firstly and then decrease sharply with the increase of $\Omega$ in the first stage, with the turning point occurring at $\Omega=1.1$. From the first to the second and then to the third stage, the reduction amplitude of the translation displacement in the $y$ direction becomes smaller and smaller, while that of torsion displacement in the second stage remains relatively large (Figure 11(b)). Moreover, the torsion displacement demonstrates a tendency toward slow increase with relatively large values of $\Omega$ in the third stage.

Comparing Figures 9, 10, and 11 reveals that, in the first stage, increasing $\Omega$ causes the torsion displacement to increase when $\Omega$ is less than or equal to 1.1. When $\Omega$ increases to 1.1 , the torsion displacement reaches its maximum value, and the translation displacement in the $x$ direction is at its minimum. The coupling effect between the translation in the $x$ direction and the torsion becomes quite strong, which is extremely unfavorable to the torsion resistance design. With the increase of $\Omega(\Omega>1.1)$, the structural seismic response gradually approaches the pure translation along the load direction, and the coupled torsional displacement and the translational displacement perpendicular to the load direction become increasingly smaller. The coupling effect between the translation in the load direction and the torsion is substantially reduced. The above finding is due to the fact that the eccentric structure with a larger $\Omega$ has a larger torsional stiffness and a larger ratio of torsional stiffness to lateral stiffness; thus, the lateral-torsional coupling effect and the torsional effect will be weak. That is to say, the structural seismic response will gradually approach the pure translation along the load direction with the increase of $\Omega$. Therefore, it will be good practice in design to achieve a large $\Omega$ value, thereby avoiding torsion failure.

4.2. The Effect of $b_{y}$ on Interstory Displacement. Figure 12 presents the effects of $b_{y}$ on the interstory translation displacements in the $x$ direction from the first to the second and then to the third stage. It can be noted from Figure 12(a) that increasing $b_{y}$ causes translation displacement in the $x$ direction to decrease uniformly. Specifically, the average reduction percentage in the translation displacement in the $x$ direction achieves $5.43 \%$ when $b_{y}$ increases 0.1 . After entering the second stage (Figure 12(b)), translation displacement in the $x$ direction on the first floor decreases gradually, while those 

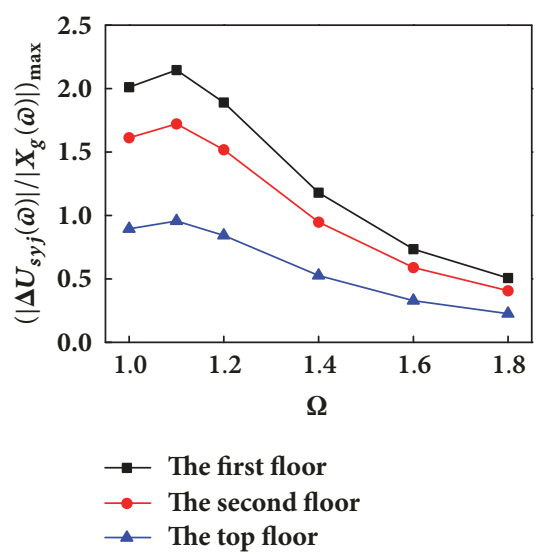

(a) The first stage

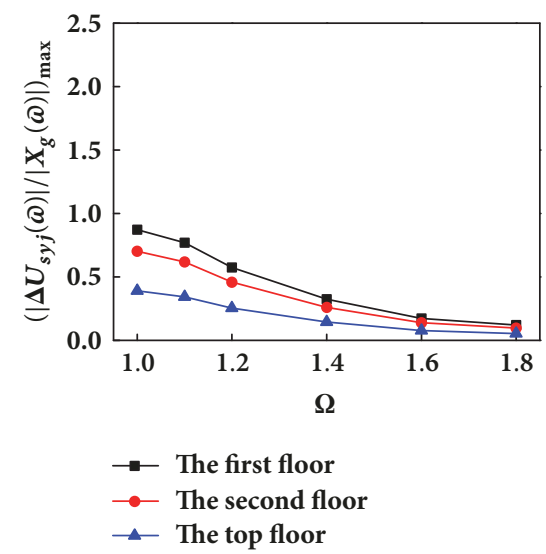

(b) The second stage

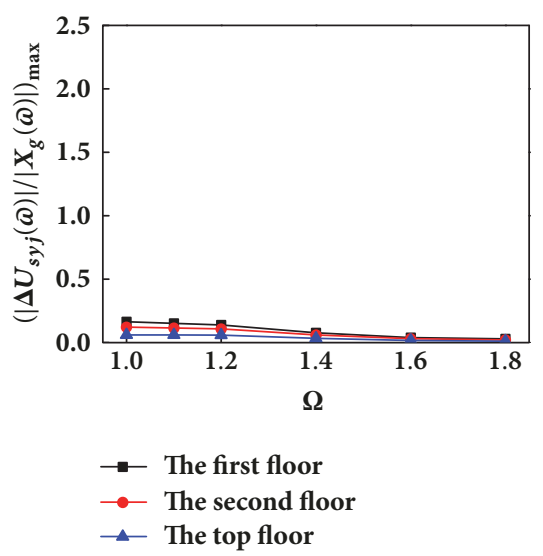

(c) The third stage

FIGURE 10: Interstory translation displacement in the $y$ direction under different $\Omega$ values.

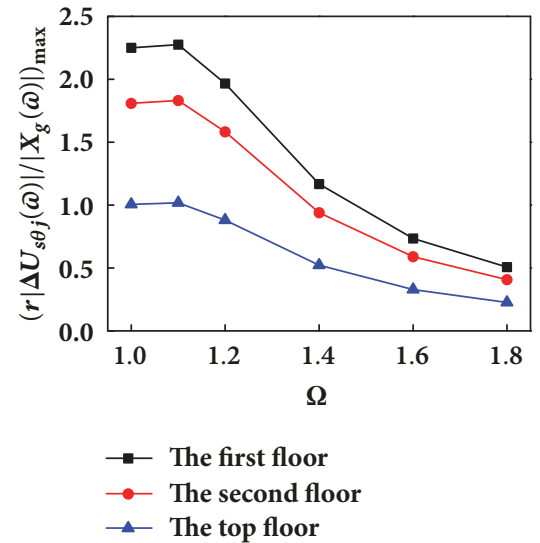

(a) The first stage
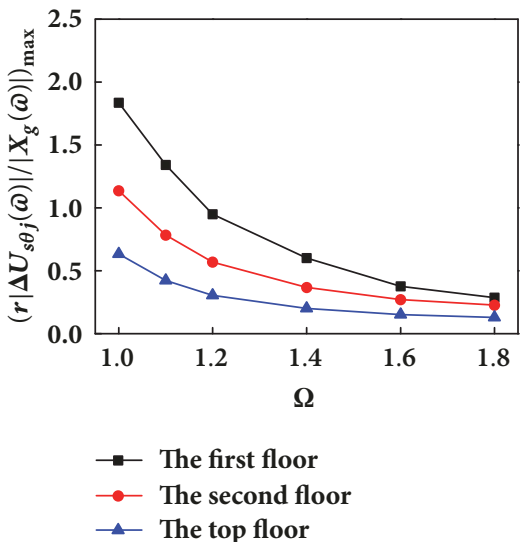

(b) The second stage

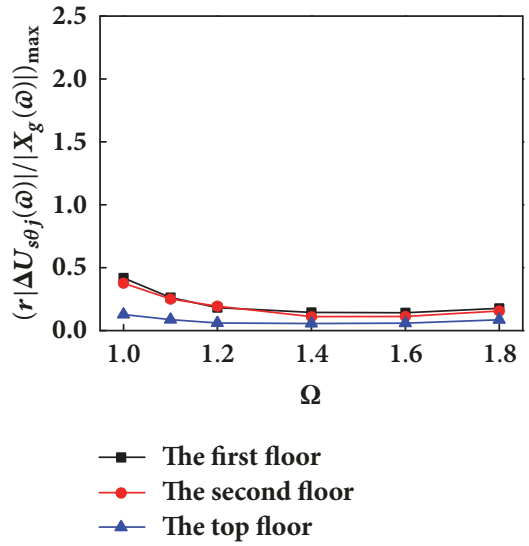

(c) The third stage

FIGURE 11: Interstory torsion displacement under different $\Omega$ values.

on the second and top floors still increase. In the third stage (Figure 12(c)), translation displacement in the $x$ direction on the first floor slightly increases, while those on the second and top floors decrease slowly, in total contrast to the second stage. These findings indicate that, in the first stage, variation tendencies of the interstory translation displacements in the $x$ direction with $b_{y}$ are similar, while different inelasticity development stages have comparably large influences on the variation regularity.

The effects of $b_{y}$ on the interstory translation displacement in the $y$ direction and the torsion displacement in different stages are, respectively, evaluated in Figures 13 and 14. It can be seen from Figures 13(a) and 14(a) that the translation displacements in the $y$ direction and the torsion displacement increase with the increase of $b_{y}$ in the first stage, and the increase percentages reduce slowly. Compared to the first stage, increasing $b_{y}$ exerts greater effects on the translational displacement in the $y$ direction and torsional displacement in the second stage when $b_{y}$ is approximately greater than or equal to 0.3 . For example, as $b_{y}$ increases from 0.3 to 0.4 , the variation percentages of the translational displacement in $y$ direction and the torsional displacement are, respectively, $4.1 \%$ and $17.9 \%$ in the first stage. In the second stage, the variation magnitudes increase to $57.9 \%$ and $65.6 \%$, respectively. In the third stage, the displacement variation amplitude is clearly reduced. Figures 13 and 14 also indicate that the variation tendencies for interstory translation displacement in the $y$ direction and torsion displacement with $b_{y}$ are similar on all floors. During the second stage, the development of structural inelasticity enhances the increase amplitude of the displacements. In the third stage, the influence of $b_{y}$ on displacements is reduced.

4.3. The Effect of $b_{x}$ on Interstory Displacement. The effects of $b_{x}$ on the interstory translation displacements in the $x$ direction in the different stages are shown in Figure 15. It is evident from Figure 15(a) that the translation displacement in the $x$ direction gradually decreases as $b_{x}$ increases in the first stage, and the reduction amplitude rises. Figures 15(b) and 15 (c) show that increasing $b_{x}$ exerts smaller effects on the variation of translation displacement in the $x$ direction in the second and third stages than in the first stage. It also can be noted from Figure 15(c) that the translation displacement in 

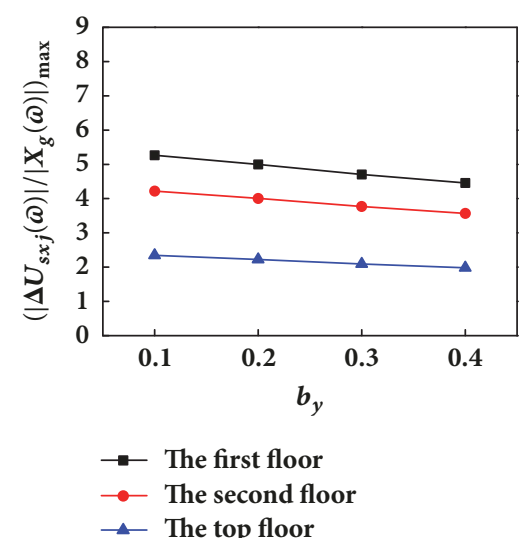

(a) The first stage
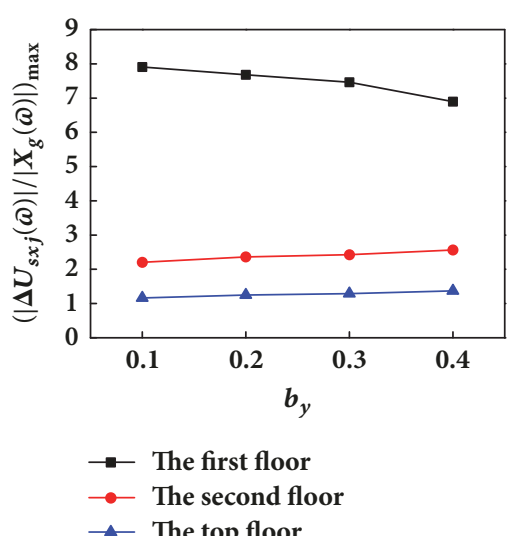

(b) The second stage

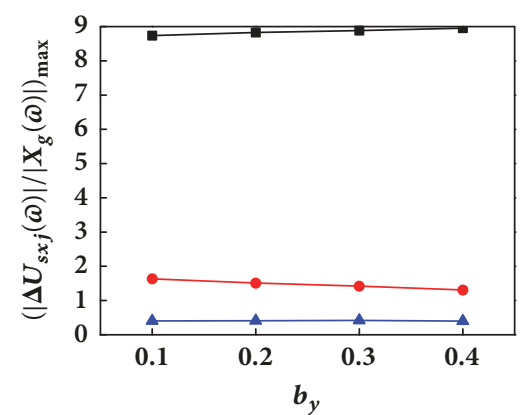

- The first floor

$\rightarrow$ The second floor

$\_$The top floor

(c) The third stage

FIGURE 12: Interstory translation displacement in the $x$ direction under different $b_{y}$ values.

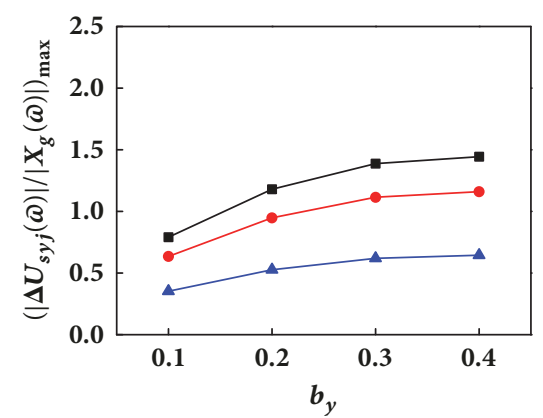

$\rightarrow$ The first floor

$\rightarrow$ The second floor

$\neg$ The top floor

(a) The first stage

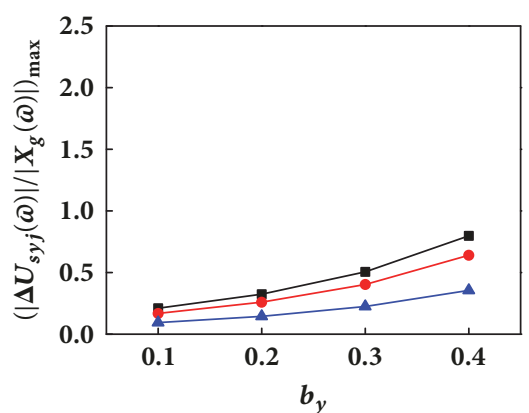

$\rightarrow$ The first floor

$\rightarrow$ The second floor

$\_$The top floor

(b) The second stage

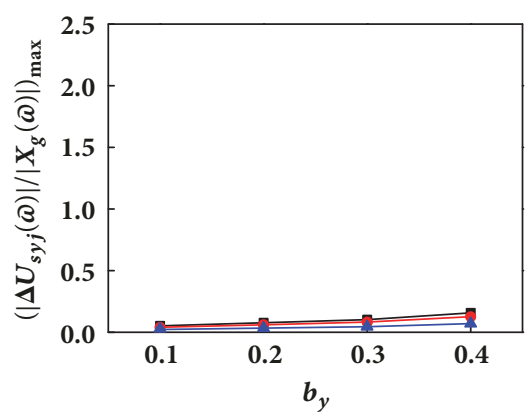

- The first floor

$\rightarrow$ The second floor

$\_$The top floor

(c) The third stage

FIGURE 13: Interstory translation displacement in the $y$ direction under different $b_{y}$ values.
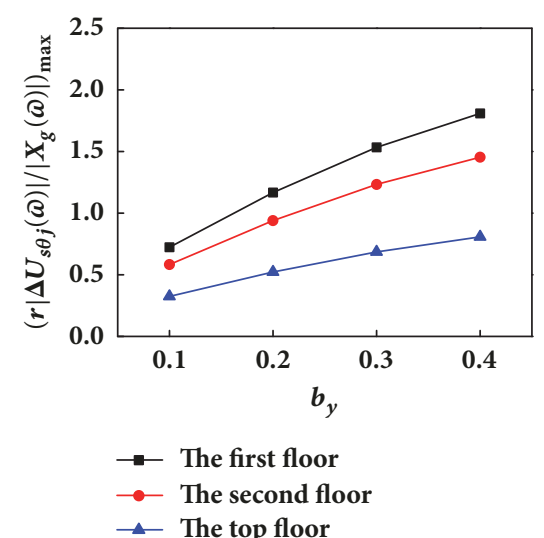

(a) The first stage
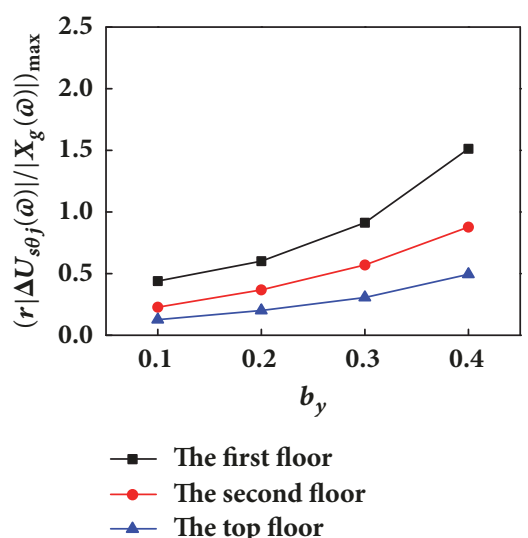

(b) The second stage

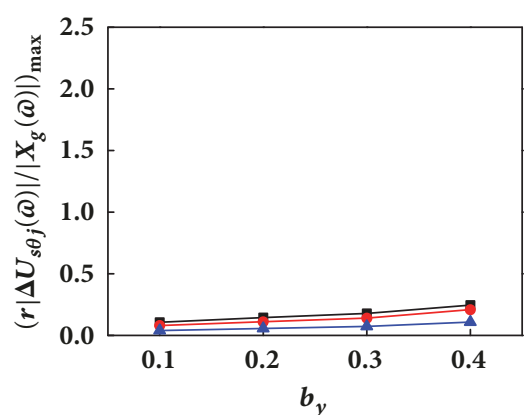

$\rightarrow$ The first floor

$\rightarrow$ The second floor

$\triangle$ The top floor

(c) The third stage

FIGURE 14: Interstory torsion displacement under different $b_{y}$ values. 


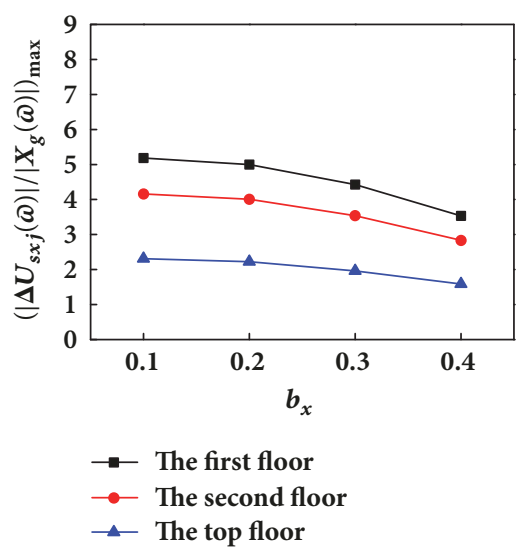

(a) The first stage

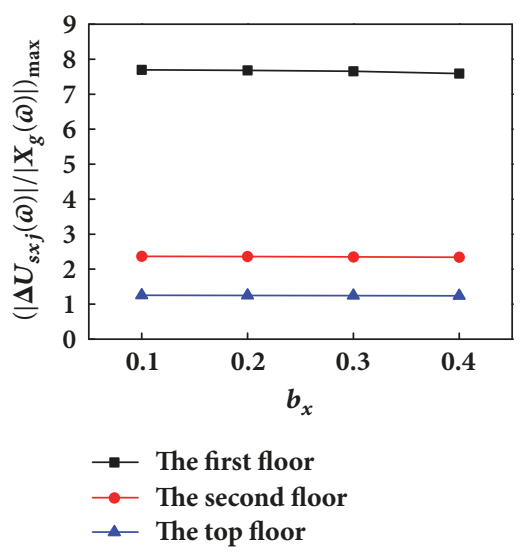

(b) The second stage

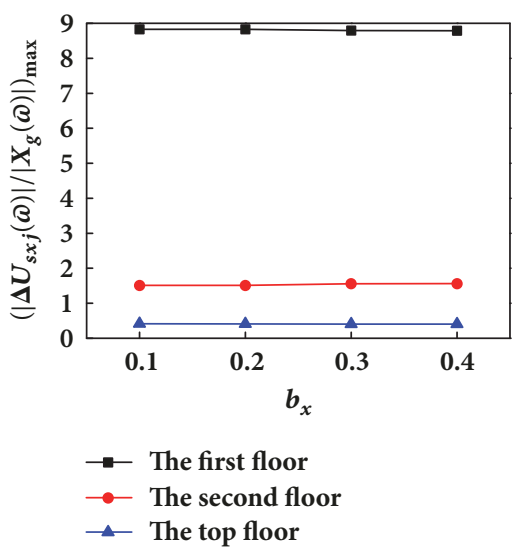

(c) The third stage

FIGURE 15: Interstory translation displacement in the $x$ direction under different $b_{x}$ values.

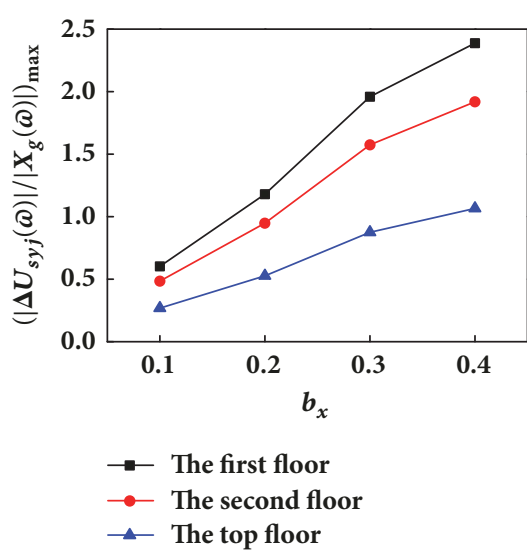

(a) The first stage
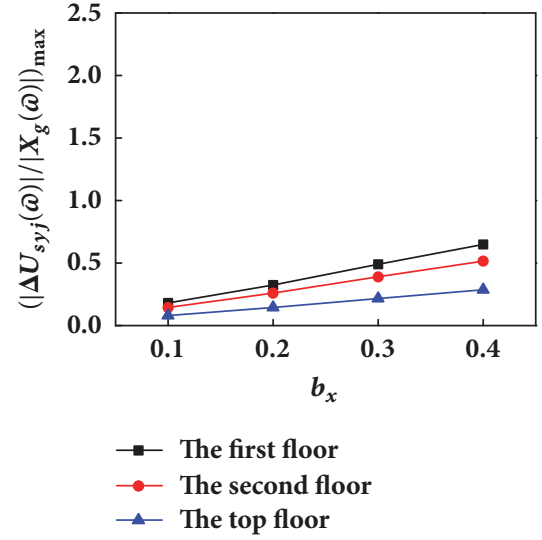

(b) The second stage

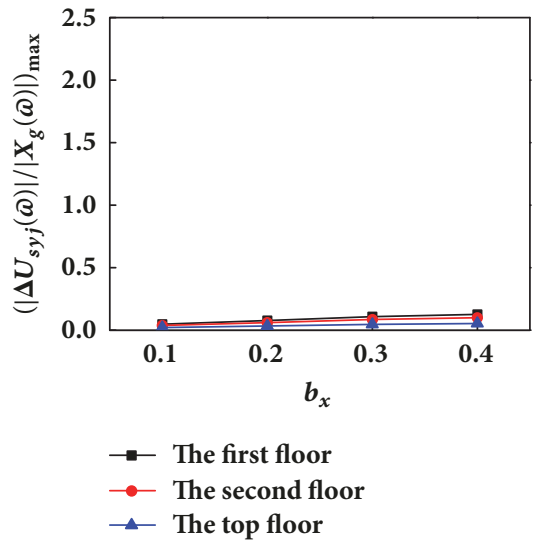

(c) The third stage

FIGURE 16: Interstory translation displacement in the $y$ direction under different $b_{x}$ values.

the $x$ direction of the second floor slowly increases and those of the other two floors slightly decrease with the increase of $b_{x}$. These findings demonstrate that the variation tendencies of interstory translation displacements in the $x$ direction with $b_{y}$ are similar in the first stage. With the yielding of the lateral load-resisting members, the influences of $b_{x}$ on the displacements are weakened in the second and third stages. And the variation regularity of interstory translation displacements in the $x$ direction is no longer consistent.

The influences of $b_{x}$ on the interstory translation displacement in the $y$ direction and the torsion displacement in different stages are given in Figures 16 and 17. It is evident from Figure 16(a) that increasing $b_{x}$ causes translation displacement in the $y$ direction to increase in the first stage, and the corresponding increasing percentage gradually decreases. Meanwhile, the torsion displacement gradually increases with the increase of $b_{x}$ and tends to be stable implied in Figure 17(a). Compared to the first stage, the second stage sees smaller variation percentages of translation displacement in the $y$ direction and the torsion displacement. It can be seen from Figure 16(c) that the translation displacement in the $y$ direction increases slightly with the increase of $b_{y}$ in the third stage. Figure 17(c) shows that the torsion displacements of the first and second floors first reduce and then increase slowly, and the torsion displacement of the top floor decreases gradually, but the variation amplitude is relatively small in this stage. These findings imply that the development of structural inelasticity weakens the influences of $b_{x}$ on displacements and changes the variation tendency of interstory torsion displacement with $b_{x}$.

The parametric analysis of lateral-torsional coupling effect of multistorey bidirectional eccentric structures has indicated that the first-order natural frequency of the eccentric structure becomes closer to that of the corresponding symmetric system from the first to the second and then to the third stage, and the lateral-torsional coupling effect in the first vibration mode is significantly reduced [17]. Accordingly, the first-order vibration mode tends toward the pure translation vibration mode in the load direction. This also determines that the translation displacement in the load direction becomes greater during this process; the coupled torsional displacement and the translational displacement in 


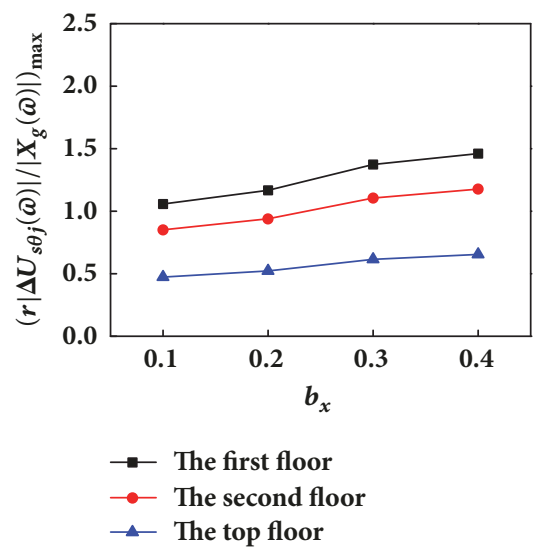

(a) The first stage

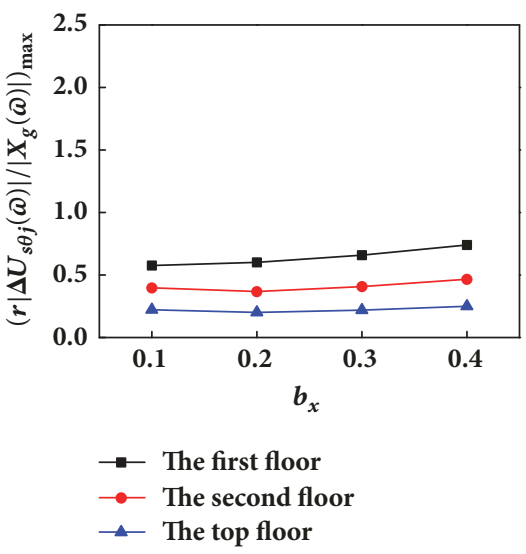

(b) The second stage

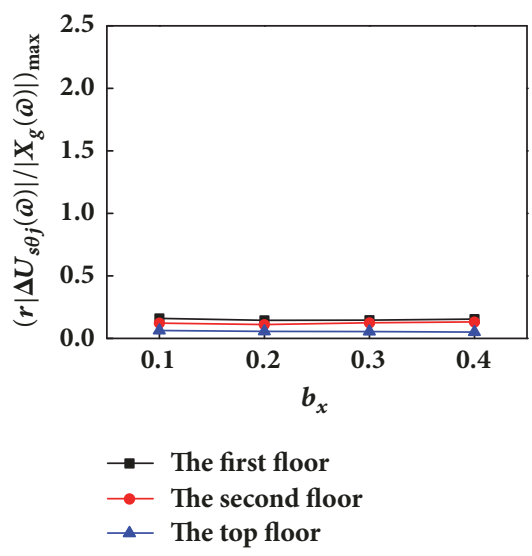

(c) The third stage

FIGURE 17: Interstory torsion displacement under different $b_{x}$ values.

the $y$ direction become increasingly smaller (Figures 9-17). In particular, the translation displacement in the $x$ direction of the first floor presents the largest increase amplitude from the first stage to the second stage. For a system with $\Omega=1.4$ and $b_{y}=b_{y}=0.2$, its translation displacement in the $x$ direction of the first floor increases $53.6 \%$ from the first to the second stage and only $14.9 \%$ from the second to the third stage. The above finding is due to the fact that the members in the load direction of floor one firstly yields in the second stage and further yield in the third stage, while members on other floors in the load direction and the members perpendicular to the load direction do not yield. The yielding of the members leads to a considerable reduction on the overall lateral stiffness in the load direction of floor one. As a result, the first floor becomes increasingly weak compared to other floors. The peak values of the interstory translational displacement transfer function in the load direction of floor one increase significantly. In the third stage, all the lateral load-resisting members in the load direction of floor one enter yield, and the members in the load direction of floor two begin to yield; therefore, the increase amplitude of the translation displacement of floor one in the load direction reduces. The overall structural seismic response gradually approaches the pure translation in the load direction, and the coupled torsional displacement and the translational displacement perpendicular to the load direction become relatively smaller. The coupling effect between the translation in the load direction and the torsion is greatly reduced.

Through the parametric analysis of the structural displacement, a general law for the seismic response of multistorey bidirectional eccentric structures varying with different parameters in the elastic and inelastic stages is obtained. These research results can provide references for structural and seismic design in engineering.

In the process of inelastic development, the actual damping of the structure is increased [36]. The damping problem in inelastic stage needs further research and discussion in basic theory and experimental verification, and this is another complex research topic. So the damping is assumed to be in direct proportion only to the linear portion of stiffness in this paper. When the stiffness-proportional damping is adopted, the actual damping in the second and third stages will be lowered, which will increase the response of the structure. This paper focuses on conducting a parametric analysis of the whole process from elastic to inelastic stage. And the influence regularities of uncoupled torsion to lateral frequency ratios and bidirectional eccentricities on the structural seismic response are mainly investigated. Due to the reason of damping change, the responses of the structure in the second and third stages are larger than the actual reactions. However, for the study of the variation law in the parametric analysis, this effect is not particularly sensitive.

\section{Discussion of Torsion-Translation Displacement Ratio under Different Eccentricities}

The parametric analysis above indicates that the bidirectional eccentricities have a considerable influence on the translation and torsion displacements of the eccentric structures, and they also affect the ratio of torsion displacement to translation displacement. This section primarily focuses on the ratio of torsion displacement to translation displacement in the load direction, and torsion-translation displacement ratio of the top floor is defined as follows:

$$
\lambda_{x 3}=\frac{\left(r\left|\triangle U_{s \theta 3}(\varpi)\right|_{\max }\right)}{\left|\triangle U_{s x 3}(\varpi)\right|_{\max }}
$$

The torsion-translation displacement ratio of the top floor $\lambda_{x 3}$ varying with coupled period ratio $T_{t} / T_{1}$ in the first stage is shown in Figure 18. $T_{\mathrm{t}}$ is the first natural period of vibration mode which is chiefly torsion, and $T_{1}$ is the first natural period of vibration mode which is primarily translational movement. According to the findings in Figure 18, an increased $T_{t} / T_{1}$ with any $b_{x}$ and $b_{y}$ causes the displacement ratio $\lambda_{x 3}$ to increase. And the lateral-torsional coupling effect of the eccentric structure becomes stronger. It also can be noted from Figure 18 that the displacement ratio changes significantly with the bidirectional eccentricities $b_{x}$ 


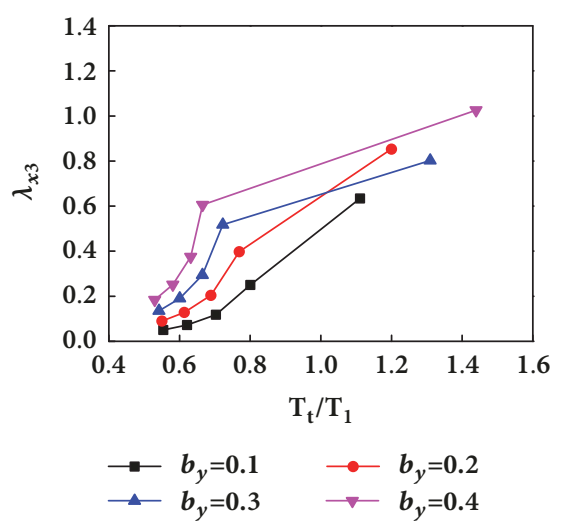

(a) $b_{x}=0.1$

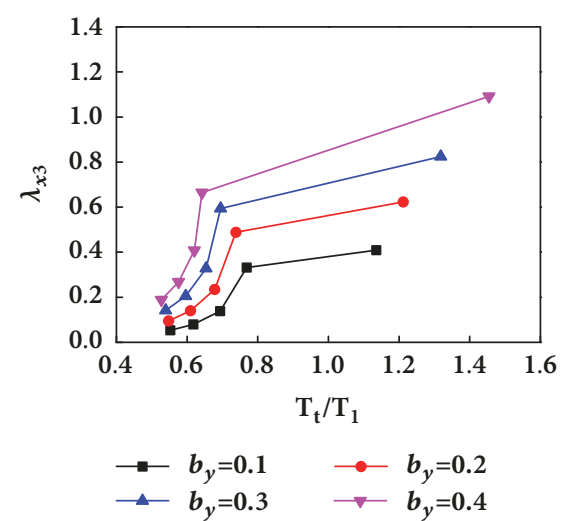

(b) $b_{x}=0.2$

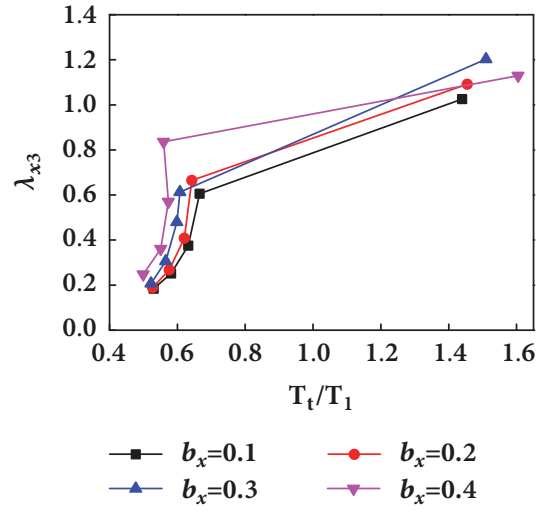

(c) $b_{y}=0.4$

FIGURE 18: Variation of $\lambda_{x 3}$ with $T_{\mathrm{t}} / T_{1}$.

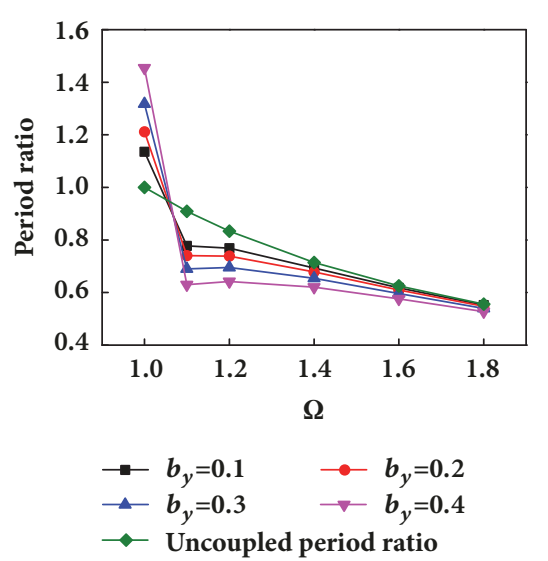

(a) $b_{x}=0.2$

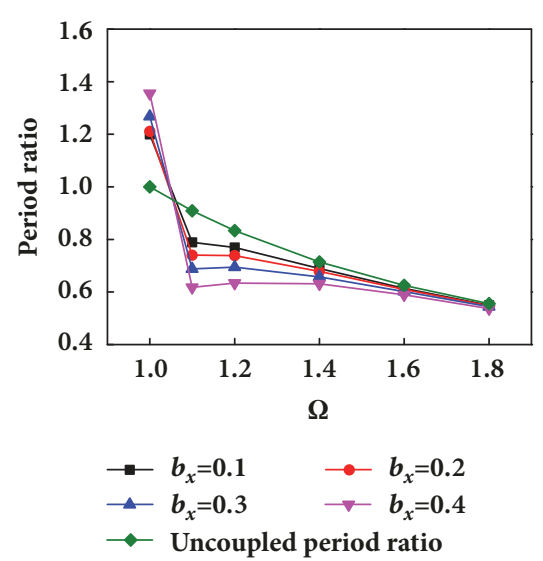

(b) $b_{y}=0.2$

FIGURE 19: Variation of coupled period ratio and noncoupled period ratio with $\Omega$.

and $b_{y}$ when $T_{\mathrm{t}} / T_{1}$ is the same. In other words, values of $T_{\mathrm{t}} / T_{1}$ of eccentric structures with different bidirectional eccentricities are remarkably different from each other when the displacement ratio $\lambda_{x 3}$ is the same. The results reveal that the structure with larger values of $b_{x}$ and $b_{y}$ has a smaller $T_{\mathrm{t}} / T_{1}$. As implied in Figures 18(a) and 18(b), the displacement ratio gradually increases as $b_{y}$ increases from 0.1 to 0.4 when the coupled period ratio is constant. Similarly, it can be seen from Figure 18(c) that increasing $b_{x}$ causes the coupled period ratio to decrease when the displacement ratio is fixed. These findings indicate that the value of $T_{\mathrm{t}} / T_{1}$ corresponding to a specific displacement ratio gradually decreases with the increase of $b_{y}$ and $b_{x}$. Similar phenomena not discussed here also occur under other values of $b_{y}$ and $b_{x}$.

Reference [37] studied the elastic lateral-torsional coupling effect of high-rise buildings with one-way mass eccentricity and the approximated calculation formula for the top floor relative torsion effect (torsion-translation displacement ratio) associated with eccentricity and $T_{t} / T_{1}$ was obtained. Based on these results, the authors proposed recommended period ratio limit values to control the relative torsion effect of one-way mass eccentricity structures. Related results have been adopted in Technical Specification for Concrete Structures of Tall Building (JGJ 3-2010) [38]. The results of this paper indicate that the lateral-torsional coupling effect of bidirectional eccentric structures is not only related to the period ratio, but also affected by the bidirectional eccentricities. High-rise buildings, which are more sensitive to the torsion effect, require additional attention.

Figure 19 displays the variation of coupled period ratios and noncoupled period ratios corresponding to different values of $\Omega$. Obviously, the noncoupled period is the reciprocal of $\Omega$, while the coupled period is obtained via calculation. It is evident from Figure 19 that the coupled period ratios of the structures with various eccentricities differ from the noncoupled period ratios. The greater the bidirectional eccentricities, the greater the difference between the coupled period ratio and noncoupled period ratio. The difference is most significant in structures with $\Omega=1$, where the coupled period ratio is as much as $31.8 \%$ greater than the noncoupled period ratio. When $\Omega$ is greater than or equal to 1.1 , the coupled period ratio is smaller than the noncoupled period ratio. As $\Omega$ increases, however, the difference reduces, although it remains notable. Even for eccentric structure with 
$\Omega=1.6$, the difference still reaches $8.47 \%$ when $b_{x}=0.2$ and $b_{y}=0.4$.

The preceding analysis clearly demonstrates the relationship between the coupled period ratio, noncoupled period ratio, and bidirectional eccentricities in multistorey bidirectional eccentric structures. Reference [37] suggested that, under the premise of satisfying the required displacement ratio when the period ratio is between 0.8 and 0.9 [38], the difference between the noncoupled period ratio and coupled period ratio is within $5 \%$. Obviously, this one-way mass eccentricity analysis result is not appropriate for multistorey structures with bidirectional stiffness eccentricities.

\section{Validation of the Dynamic Response of Eccentric Simplified Model}

6.1. Construction of the 3D Refined Model. Section 3.1 has already analyzed and discussed the applicability of the simplified model in the inelastic stage. To further validate the accuracy and reliability of the proposed simplified model in the parametric analysis of the seismic response, a corresponding 3D refined model for the three-storey eccentric structure with its plane layout as Figure 1 is established. And the dynamic responses of the proposed simplified model are validated by the nonlinear dynamic time history analysis. The beam element of BEAM188 which can define the crosssection dimension is applied to simulate the frame beams and columns, and the shell element of SHELL63 is used to simulate the floor slab. The related structural parameters of the three-storey eccentric structure are the same as those in 3.1 Section. When the nonlinear dynamic time history analysis of the 3D refined model is conducted by ANSYS, the simulation process becomes difficult if the structure directly utilizes the force-displacement resilience model. Hence, the elastic-plastic constitutive models of the beam and column elements adopt the bilinearity isotropic hardening model (BISO) which follows flow rules related to Von Mises yielding. Only the elastic modulus before yielding, the tangent modulus after yielding, and the yield strength should be defined in ANSYS, and the tangent modulus after yielding is also set as $10 \%$ of the elastic modulus [39]. The stiffness matrix coefficient calculation of damping defined by ANSYS is the same as the damping coefficient defined in Section 2.2.

Since this study focuses on the overall analysis of the structure and considers the coupling effect between translational displacement and torsional displacement of the eccentric structure, an integral analysis model of reinforced concrete is selected. It is assumed that rebars are dispersed in the whole element and the element is considered as a continuous homogeneous material. The contribution of rebars to the whole structure is realized by increasing the material elastic modulus via the stiffness EI equivalence principle [40].

$$
E I=E_{c} I_{c}+E_{s} I_{s}
$$

in which $E$ and $I$ are, respectively, the elastic modulus and cross-section inertia moment; superscripts $c$ and $s$ refer to the concrete part and rebar part, respectively. The moment of

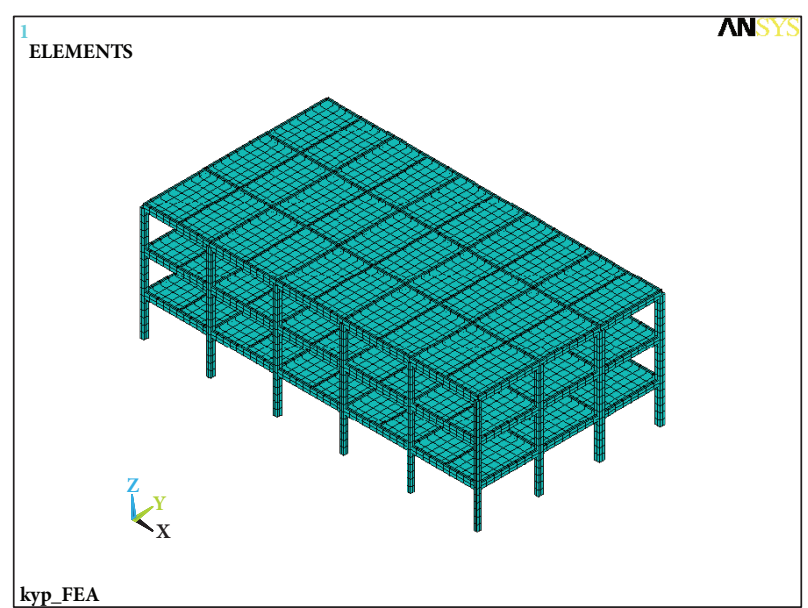

FIGURE 20: The 3D refined model corresponding to the simplified model.

inertia of the concrete is calculated considering the uncracked cross-section.

The dimension of mesh should also be taken into consideration during the construction of the finite element model. When the mesh size is small, the calculation accuracy is high, but due to the high degrees of freedom, the required calculation time, calculation amount, and memory space are great accordingly. Meanwhile, when the mesh size is smaller than $5 \mathrm{~cm}$, the calculation may become difficult. Similarly, the mesh size cannot be too oversized; otherwise, the calculation accuracy will be affected. Based on above aspects, the 3D refined model is constructed, as shown in Figure 20.

6.2. Selection of Seismic Waves. The selection of seismic waves should meet the requirements of three seismic oscillation elements, i.e., spectral characteristics, time of duration, and amplitude. The spectral characteristics can be described by the seismic influence coefficient curves and determined according to the site classification and designed seismic grouping. Reference [38] stipulates that the last duration of seismic waves should not be less than five times of the building basic period and $15 \mathrm{~s}$, and the time interval of seismic waves can be set as $0.01 \mathrm{~s}$ or $0.02 \mathrm{~s}$. The NS component of the 1976 Tianjin earthquake record, the NS component of the 1940 EL-Centro earthquake record, and an artificial Tianjin wave are selected as the external load of dynamic analysis. The selected seismic waves include a main energy section lasting duration of $15 \mathrm{~s}$ and an interval of $0.02 \mathrm{~s}$. The seismic fortification intensity in Tianjin is 7 degrees. According to the Code for Seismic Design of Building [30], the basic seismic acceleration is designed as $0.15 \mathrm{~g}$. To conduct analyses under frequently occurred earthquake and rare earthquake, the seismic waves are proportionally increased to maximum values of $0.55 \mathrm{~m} / \mathrm{s}^{2}$ and $3.1 \mathrm{~m} / \mathrm{s}^{2}$.

The acceleration time history records of these three seismic waves (amplitude increased to $3.1 \mathrm{~m} / \mathrm{s}^{2}$ ) and the corresponding spectra are shown in Figures 21 and 22, respectively. The frequency components of these three seismic waves are 


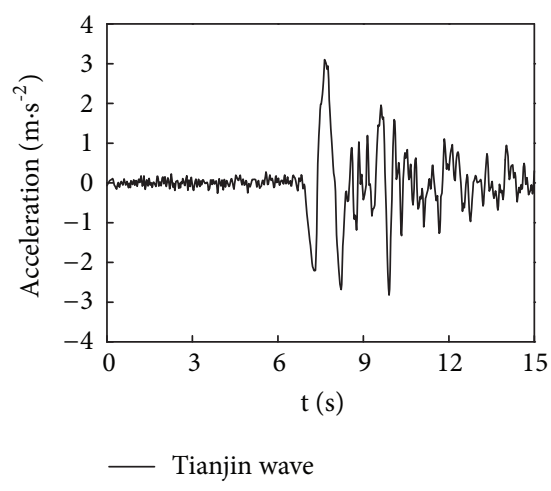

(a) Tianjin wave

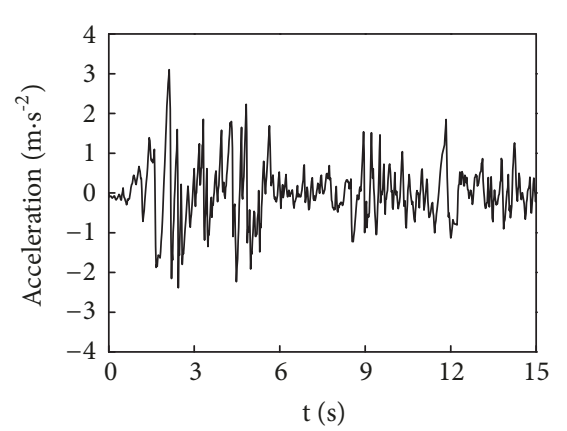

- EL-Centro wave

(b) EL-Centro wave

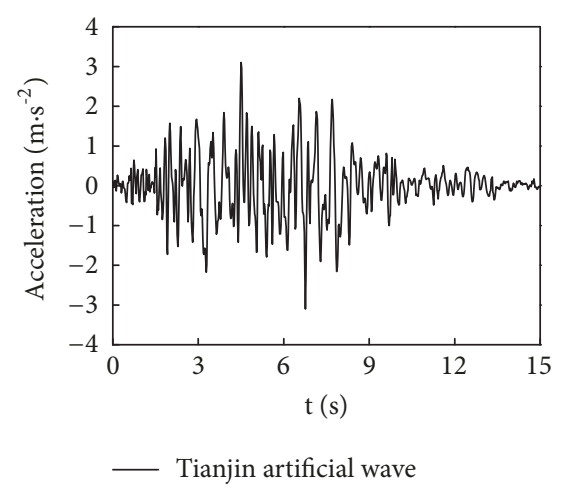

(c) Tianjin artificial wave

Figure 21: Acceleration time history curve of seismic wave.

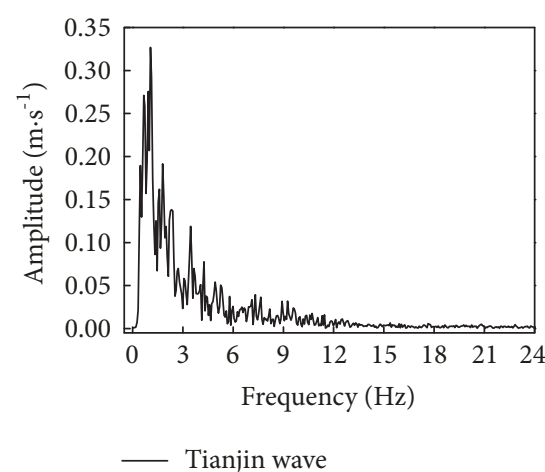

(a) Tianjin wave

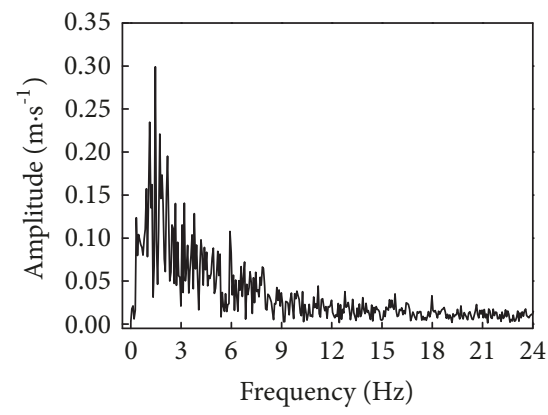

_ EL-Centro wave

(b) EL-Centro wave

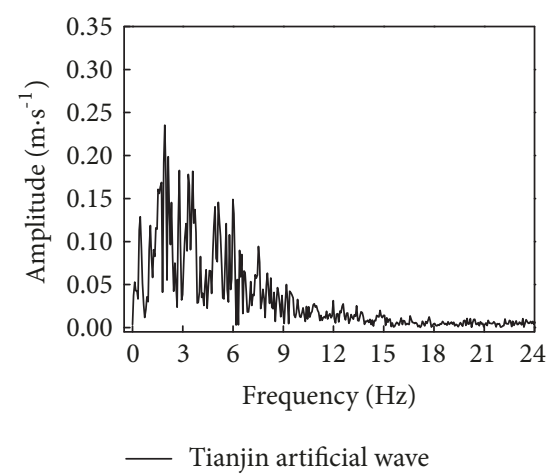

(c) Tianjin artificial wave

FIGURE 22: Seismic wave frequency spectra.

quite different. The Tianjin wave is mainly composed of low frequency components, and the high frequency content is low. The frequency components of EL-Centro waves are moderate, while the high frequency components of Tianjin artificial wave are relatively high. The frequency components and preeminent frequencies of seismic waves have a great influence on the dynamic responses of structures. Therefore, the conclusions obtained by the selected waves with different frequencies components will be more representative.

\subsection{Comparison of the Dynamic Response of 3D Refined Model} and Simplified Model. The dynamic time history analyses of both simplified model and 3D refined model are carried out under the action of the ground motion in the $x$ direction. And the dynamic responses of the two models are compared. Under the action of frequently occurred earthquake, the structure is in the elastic stage. And under the action of rare earthquake, the structure enters the inelastic stage. The time history curves of the top floor displacement at the center of mass under the action of EL-Centro wave are shown in Figures 23 and 24. $u_{x 3}$ and $u_{y 3}$ denote the top floor translational displacement in the $x$ and $y$ directions, respectively. And $u_{\theta 3}$ represents the top floor torsional angle. The corresponding peak values of the top floor displacement are given in Tables 1 and 2. The peak value of the top floor torsional displacement is equal to the peak value of the torsional angle multiplying the corresponding radius of rotation.

It is evident from Figure 23 that the displacement time history curve of the simplified model is in good agreement with that of the 3D refined model under the action of ELCentro wave. Under the action of the other two kinds of seismic waves, the displacement time history curves of two models are also coincided with each other. Restricted to the length of the article, the corresponding displacement time history curves are not presented in the paper. It also can be seen from Table 1 that the peak values of displacement in the $x$ direction of the two models deviate within 5\%. Meanwhile, the peak values of translational displacement in the $y$ direction and the torsional displacement of the two models have differences within $10 \%$. Figure 24 displays that the displacement time history curves of the two models differ a little under the action of rare earthquake but still agree with each other generally. As evidenced in Table 2, the peak values of translation displacement in the $x$ direction differ within $10 \%$. For the rest displacement peak values, beside two values deviate greater than $13 \%$, the rest values all vary within $10 \%$.

In this paper, the overall response of the structure under the action of ground motion in the $x$ direction is mainly analyzed. In the inelastic stage, the peak values of displacement in the $y$ direction and torsional displacement have 
TABLE 1: The peak values of the top floor displacement under frequently occurred earthquake.

\begin{tabular}{|c|c|c|c|c|}
\hline Seismic wave & $\begin{array}{l}\text { Displacement peak } \\
\text { values }(\mathrm{mm})\end{array}$ & $3 \mathrm{D}$ refined model & Simplified model & Error \\
\hline \multirow{3}{*}{ Tianjin wave } & $u_{x 3}$ & -5.270 & -5.240 & $0.57 \%$ \\
\hline & $u_{y 3}$ & 0.775 & 0.683 & $11.93 \%$ \\
\hline & $r u_{\theta 3}$ & -1.119 & -1.186 & $-6.01 \%$ \\
\hline \multirow{3}{*}{ EL-Centro wave } & $u_{x 3}$ & 4.320 & 4.480 & $-3.70 \%$ \\
\hline & $u_{y 3}$ & -0.846 & -0.807 & $4.61 \%$ \\
\hline & $r u_{\theta 3}$ & -0.953 & -1.029 & $-8.04 \%$ \\
\hline \multirow{3}{*}{ Tianjin artificial wave } & $u_{x 3}$ & 4.190 & 4.020 & $4.06 \%$ \\
\hline & $u_{y 3}$ & 0.843 & 0.782 & $7.29 \%$ \\
\hline & $r u_{\theta 3}$ & -0.086 & -0.080 & $6.75 \%$ \\
\hline
\end{tabular}

TABLE 2: The peak values of the top floor displacement under rare earthquake.

\begin{tabular}{|c|c|c|c|c|}
\hline Seismic wave & $\begin{array}{c}\text { Displacement peak } \\
\text { values }(\mathrm{mm})\end{array}$ & $3 \mathrm{D}$ refined model & Simplified model & Error \\
\hline \multirow{3}{*}{ Tianjin wave } & $u_{x 3}$ & 25.640 & 23.140 & $9.75 \%$ \\
\hline & $u_{y 3}$ & -2.310 & -2.620 & $-13.42 \%$ \\
\hline & $r u_{\theta 3}$ & -5.551 & -6.159 & $-10.95 \%$ \\
\hline \multirow{3}{*}{ EL-Centro wave } & $u_{x 3}$ & 23.527 & 25.145 & $-6.88 \%$ \\
\hline & $u_{y 3}$ & -4.270 & -3.870 & $9.37 \%$ \\
\hline & $r u_{\theta 3}$ & 5.469 & 6.331 & $-15.77 \%$ \\
\hline \multirow{3}{*}{ Tianjin artificial wave } & $u_{x 3}$ & 22.601 & 23.473 & $-3.86 \%$ \\
\hline & $u_{y 3}$ & 4.310 & 3.820 & $11.37 \%$ \\
\hline & $r u_{\theta 3}$ & -5.871 & -5.172 & $11.90 \%$ \\
\hline
\end{tabular}

relatively large errors, but their actual values are very small and have limited influence on the structure. The main structural response is the translation displacement in the $x$ direction. And the translation displacements in the $x$ direction of the two models all have minor errors in both the elastic and inelastic stages, which are within the acceptance of engineering applications. Hence, for the parametric analysis of the coupling effect between translation and torsional displacement of the eccentric structure under the external load in the $x$ direction conducted in this study, the simplified eccentric model proposed is accurate and reliable.

\section{Conclusions}

Based on the simplified multistorey bidirectional eccentric model, this study conducted a full-process parametric analysis of structural seismic response from elastic stage to inelastic stage. It can be clearly seen that the lateral-torsional coupling behaviours in the inelastic stage are remarkably different from that in the elastic stage. The variations of structural seismic response with parameters are related to the degree of inelasticity development. The following specific conclusions can be drawn:

(1) Taking a typical multistorey bidirectional regular eccentric frame system as an illustrative example, a simplified bidirectional asymmetric multistorey dual lateral load-resisting model is constructed. The simplified model is applicable to inelastic parametric analysis. The development of simplified model laid the foundations for the successive parametric analyses in the following work.

(2) During the full process from elastic stage to inelastic stage, the natural frequency of eccentric frame structures with different layers exhibits three-stage variation regularity. Different simplification treatments were conducted on these three stages. The second stage, which plays a key role during analysis, is fitted into a slant line via the least-squares method with a linear relation to the loading coefficient. Based on this, three-stage analyses are defined to provide convenience for parametric analysis of different inelastic development stages. The corresponding dynamic stiffness matrices and motion equations in different loading stages are derived.

(3) Based on the three defined analysis stages, the fullprocess parametric analysis of lateral-torsional coupling behaviour of the multistorey bidirectional eccentric structure is conducted for the first time from elastic to inelastic stage. The variation tendencies of the lateral-torsional coupling behaviours under the major parameters, including the uncoupled torsion to lateral frequency ratios and eccentricities with 


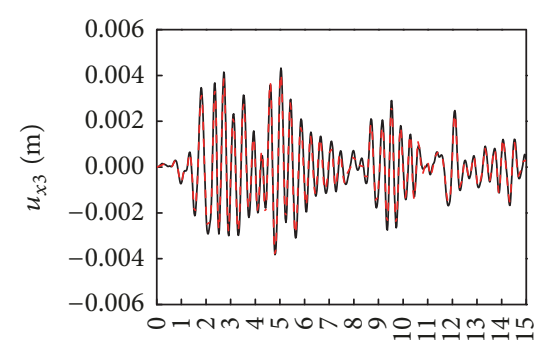

$\mathrm{t}(\mathrm{s})$

_ The 3D refined model
$-\ldots$ The simplified model

(a) The displacement in the $x$ direction

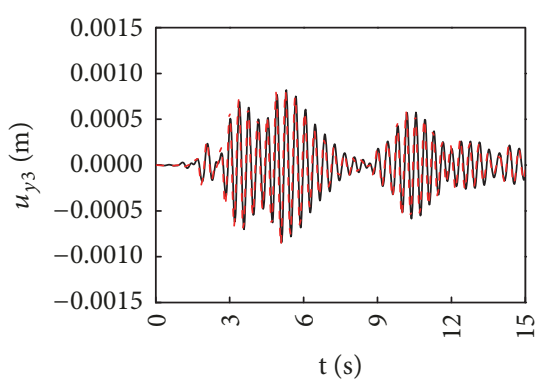

_ The 3D refined model
$-\ldots$ The simplified model

(b) The displacement in the $y$ direction

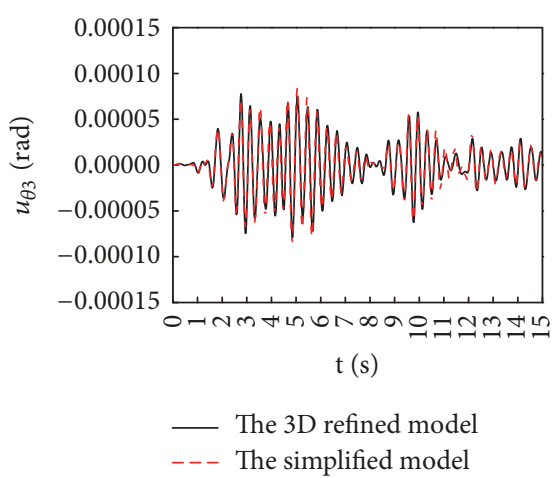

(c) The torsional angle

FIGURE 23: The top floor displacement curves at the center of mass under frequently occurred earthquake (EL-Centro wave).

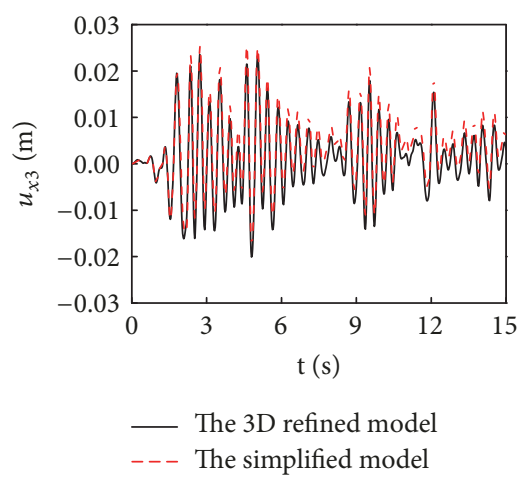

(a) The displacement in the $x$ direction

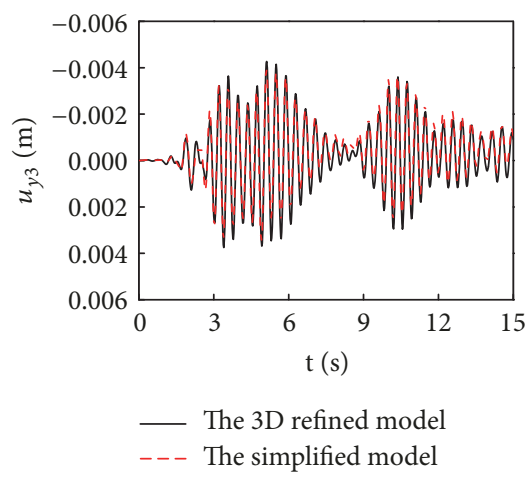

(b) The displacement in the $y$ direction

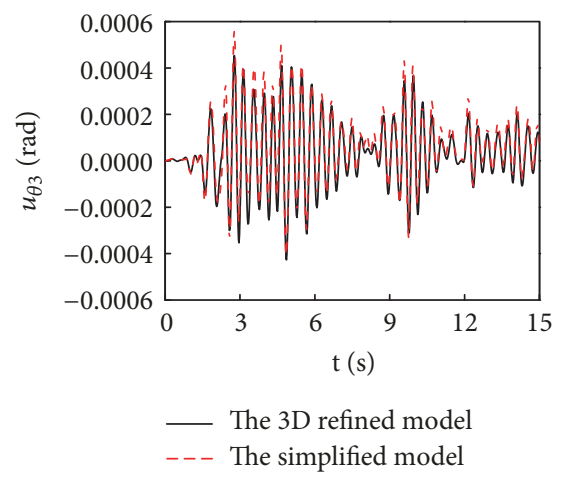

(c) The torsional angle

FIGURE 24: The top floor displacement curves at the center of mass under rare earthquake (EL-Centro wave).

different values and stages, are analyzed. The general laws of each parameter affecting the lateral-torsional coupling behaviours in three stages are concluded. The analysis results reported that the coupling effect between the translation in the load direction and the torsion is the strongest when $\Omega$ is equal to 1.1, which is extremely unfavorable for the torsion resistance design.

(4) From the first to the second and then to the third stage, the overall structural seismic response gradually approaches the pure translation in the load direction, and the coupled torsional displacement and the translational displacement perpendicular to the load direction become relatively smaller. The coupling effect between the translation in the load direction and the torsion is greatly reduced.

(5) Compared to noncoupled period ratios, coupled period ratios are different under different eccentricities. The greater the bidirectional eccentricities, the greater the difference between the coupled period ratio and noncoupled period ratio. Analytical results indicate that the lateral-torsional coupling effect of bidirectional eccentric structures is closely related to both the period ratio and the bidirectional eccentricities. High-rise buildings, which are more sensitive to the torsion effect, require additional attention. It is suggested that the effect of eccentricities should be considered when the coupled period ratio is limited by the relevant specifications.

(6) Through the nonlinear dynamic time history analysis of the proposed simplified model and the corresponding 3D refined model established on ANSYS software, the dynamic response of the simplified model is verified. Results show that the displacement time history curves of the two models agree well with each other, and the differences in the displacement peak values of the elastic and inelastic stages are within $5 \%$ and $10 \%$, respectively. It is proved that the simplified model proposed in this paper is completely feasible for the parametric analysis of the overall response of the eccentric structure along the force direction, and the results are accurate and reliable.

\section{Conflicts of Interest}

The authors declare that there are no conflicts of interest regarding the publication of this paper. 


\section{Acknowledgments}

This work was financially supported by the National Science Foundation Project (Research Project no. 51278335), National Youth Science Foundation Project (Research Project no. 51208356), and the National Science Foundation Project (Research Project no. 51478312), China.

\section{References}

[1] M. N. Bugeja, D. P. Thambiratnam, and G. H. Brameld, "The influence of stiffness and strength eccentricities on the inelastic earthquake response of asymmetric structures," Engineering Structures, vol. 21, no. 9, pp. 856-863, 1999.

[2] C.-F. Yiu, C.-M. Chan, M. Huang, and G. Li, "Evaluation of lateral-torsional coupling in earthquake response of asymmetric multistory buildings," The Structural Design of Tall and Special Buildings, vol. 23, no. 13, pp. 1007-1026, 2014.

[3] S. Karimiyan, A. H. Kashan, and M. Karimiyan, "Progressive collapse vulnerability in 6-Story RC symmetric and asymmetric buildings under earthquake loads," Earthquake and Structures, vol. 6, no. 5, pp. 473-494, 2014.

[4] G. Manoukas, A. Athanatopoulou, and I. Avramidis, "Multimode pushover analysis for asymmetric buildings under biaxial seismic excitation based on a new concept of the equivalent single degree of freedom system," Soil Dynamics and Earthquake Engineering, vol. 38, pp. 88-96, 2012.

[5] F. Khoshnoudian and A. I. Azad, "Effect of two horizontal components of earthquake on nonlinear response of torsionally coupled base isolated structures," The Structural Design of Tall and Special Buildings, vol. 20, no. 8, pp. 986-1018, 2011.

[6] G.-B. Bu, J. Cai, J. Zhou, and K.-N. Li, "Elastoplastic aseismic research on eccentric structures subjected to velocity pulse-like ground motion," Gongcheng Lixue/Engineering Mechanics, vol. 32, no. 2, pp. 131-138, 2015.

[7] R. Hejal and A. K. Chopra, "Lateral-torsional coupling in earthquake response of frame buildings," Journal of Structural Engineering (United States), vol. 115, no. 4, pp. 852-867, 1989.

[8] Y. W. Wang, A Study on the Inelastic Earthquake Response of the Asymmetric-Plan Structure, Chongqing University, Chongqing, China, 2003.

[9] C. L. Kan and A. K. Chopra, "Torsional coupling and earthquake response of single elastic and inelastic systems," Journal of Structural Division ASCE, vol. 107, no. 4, pp. 1569-1588, 1981.

[10] W. K. Tso and A. W. Sadek, "Inelastic seismic response of simple eccentric structures," Earthquake Engineering \& Structural Dynamics, vol. 13, no. 2, pp. 255-269, 1985.

[11] Y. Bozorgnia and W. K. Tso, "Inelastic Earthquake Response of Asymmetric Structures," Journal of Structural Engineering, vol. 112, no. 2, pp. 383-400, 1986.

[12] W. K. Tso and C. M. Wong, "Seismic displacements of torsionally unbalanced buildings," Earthquake Engineering \& Structural Dynamics, vol. 24, no. 10, pp. 1371-1387, 1995.

[13] J. L. Humar and P. Kumar, "Effect of orthogonal inplane structural elements on inelastic torsional response," Earthquake Engineering \& Structural Dynamics, vol. 28, no. 10, pp. 10711097, 1999.

[14] C. Liu, Study on Torsional Response of Eccentric Structures under Seismic Action, Changsha, China, Hunan University, 2007.

[15] D. Marušić and P. Fajfar, "On the inelastic seismic response of asymmetric buildings under bi-axial excitation," Earthquake
Engineering \& Structural Dynamics, vol. 34, no. 8, pp. 943-963, 2005.

[16] G. Magliulo and R. Ramasco, "Seismic response of three-dimensional $\mathrm{r} / \mathrm{c}$ multi-storey frame building under uni- and bi-directional input ground motion," Earthquake Engineering of Structural Dynamics, vol. 36, no. 12, pp. 1641-1657, 2007.

[17] X. Jiang and Y. Kuang, "Inelastic parametric analysis of two-way asymmetrical multi-storey buildings," Advances in Structural Engineering, vol. 19, no. 5, pp. 806-824, 2016.

[18] M. Bosco, A. Ghersi, E. M. Marino, and P. P. Rossi, "Generalized corrective eccentricities for nonlinear static analysis of buildings with framed or braced structure," Bulletin of Earthquake Engineering, vol. 15, no. 11, pp. 4887-4913, 2017.

[19] X. H. Cai, R. F. Wu, and S. B. Xu, "Research on the inelastic seismic responses of shear type multistorey buildings with regular asymmetry," Applied Mathematics and Mechanics, vol. 22, no. 11, pp. 1129-1134, 2001.

[20] K. G. Stathopoulos and S. A. Anagnostopoulos, "Inelastic torsion of multistorey buildings under earthquake excitations," Earthquake Engineering \& Structural Dynamics, vol. 34, no. 12, pp. 1449-1465, 2005.

[21] K. G. Stathopoulos and S. A. Anagnostopoulos, "Inelastic earthquake response of single-story asymmetric buildings: An assessment of simplified shear-beam models," Earthquake Engineering \& Structural Dynamics, vol. 32, no. 12, pp. 1813-1831, 2003.

[22] S. M. Rizwan and Y. Singh, "Effect of Strength Eccentricity on Torsional Behaviour of RC Frame Buildings," Journal of The Institution of Engineers (India): Series A, vol. 93, no. 1, pp. 1526, 2012.

[23] A. M. Halabian and M. S. Birzhandi, "Inelastic response of bieccentric-plan asymmetric reinforced concrete buildings," Proceedings of the Institution of Civil Engineers - Structures and Buildings, vol. 167, no. 8, pp. 469-485, 2014.

[24] R. K. Goel and A. K. Chopra, "Inelastic seismic response of onestorey, asymmetric-plan systems: Effects of stiffness and strength distribution," Earthquake Engineering \& Structural Dynamics, vol. 19, no. 7, pp. 949-970, 1990.

[25] R. Hejal and A. K. Chopra, "Earthquake response of torsionally coupled, frame buildings," Journal of Structural Engineering (United States), vol. 115, no. 4, pp. 834-851, 1989.

[26] X. N. Duan and A. M. Chandler, "Inelastic seismic response of code-designed multistorey frame buildings with regular asymmetry," Earthquake Engineering \& Structural Dynamics, vol. 22, no. 5, pp. 431-445, 1993.

[27] A. M. Chandler and X. N. Duan, "A modified static procedure for the design of torsionally unbalanced multistorey frame buildings," Earthquake Engineering \& Structural Dynamics, vol. 22, no. 5, pp. 447-462, 1993.

[28] S. A. Anagnostopoulos, C. Alexopoulou, and K. G. Stathopoulos, "An answer to an important controversy and the need for caution when using simple models to predict inelastic earthquake response of buildings with torsion," Earthquake Engineering \& Structural Dynamics, vol. 39, no. 5, pp. 521-540, 2010.

[29] A. K. Chopra, Dynamics of Structures. Theory Applications to Earthquake Engineering, Pearson Prentice Hall, Upper Saddle River, NJ, USA, 3rd edition, 2007.

[30] GB50011-2010, Code for Seismic Design of Building, China Architecture and Building Press, Beijing, China, 2010.

[31] W. Wu and H. A. Smith, "Efficient modal analysis for structures with soil-structure interaction," Earthquake Engineering \& Structural Dynamics, vol. 24, no. 2, pp. 283-299, 1995. 
[32] X. P. Zhang, Non-linear Analysis of Reinforced Concrete Aseismic Structures, Sciense Press, Beijing, China, 2003.

[33] Z. He and J. P. Ou, Non-linear Analysis of Reinforced Concrete Structure, Harbin Institute of Technology Press, Harbin, China, 2007.

[34] H. S. Zhang, Study on Mixed Constraint Modal Synthesis Method for Local Nonlinear of Soil-Structure Interaction, Tianjin University, Tianjin, China, 2015.

[35] H. N. Li and Z. Q. Yin, "Torsionally coupled response of eccentric structures to multi-dimensional ground motions," Earthquake Engineering and Engineering Dynamics, vol. 8, no. 4, pp. 45-53, 1988.

[36] Z. Yang, J. Huang, and J. Tian, "On damping in elastic-plastic static and dynamic method under rare earthquakes," Earthquake Engineering and Engineering Vibration, vol. 29, no. 6, pp. 115-120, 2009.

[37] P. F. Xu, J. F. Huang, and C. J. Wei, "Response of Torsional Vibration of Tall Building Structures Induced by Seismic Action," Building Science, vol. 16, no. 1, pp. 1-6, 2000.

[38] JGJ 3-2010, Technical Specification for Concrete Structures of Tall Building, China Architecture and Building Press, Beijing, China, 2011.

[39] X. M. Wang, Numerical Analysis of Engineering Structure by ANSYS, China Communications Press, Beijing, China, 1st edition, 2007.

[40] B. Chen, X. L. Lv, P. Z. Li, and Y. Q. Chen, "Modeling of dynamic soil-structure interaction by ANSYS program," Earthquake Engineering and Engineering Vibration, vol. 22, no. 1, pp. 126131, 2002. 


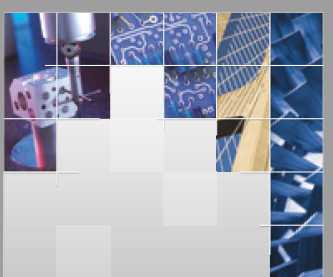

\section{Enfincering}
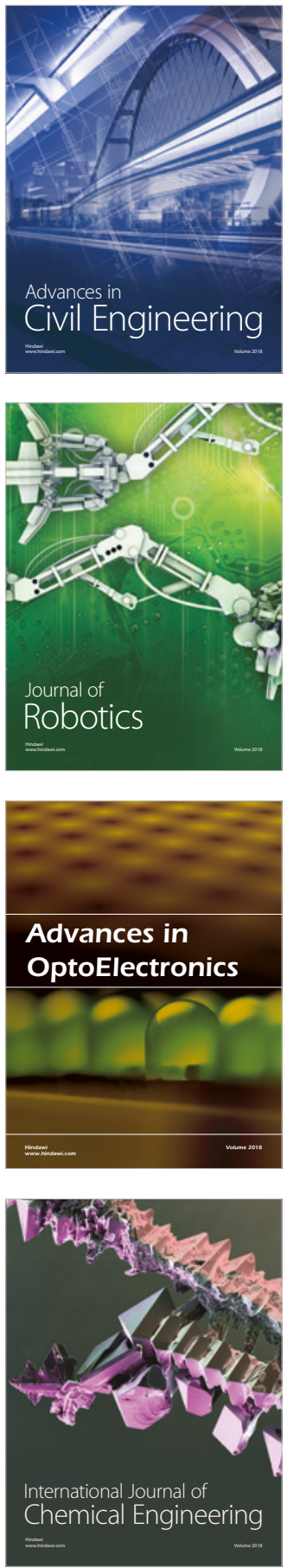

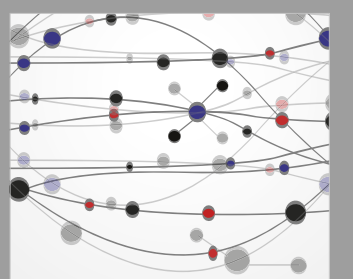

\section{Rotating \\ Machinery}

The Scientific World Journal

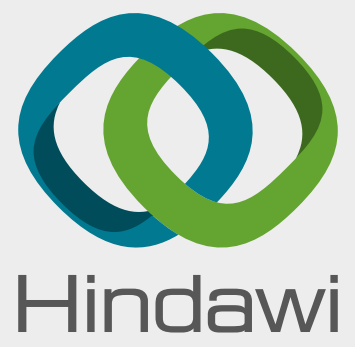

Submit your manuscripts at

www.hindawi.com
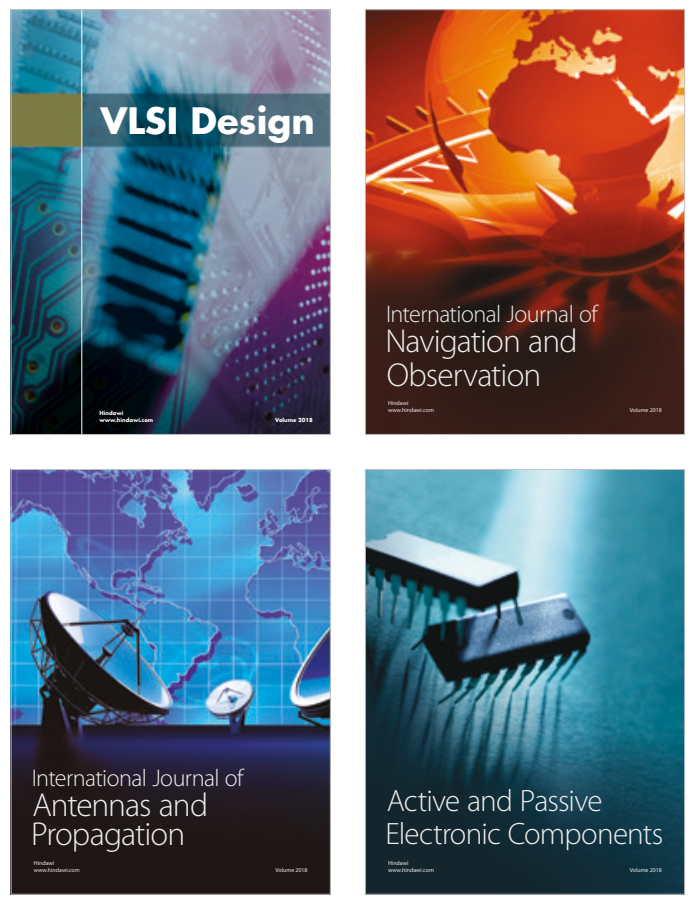
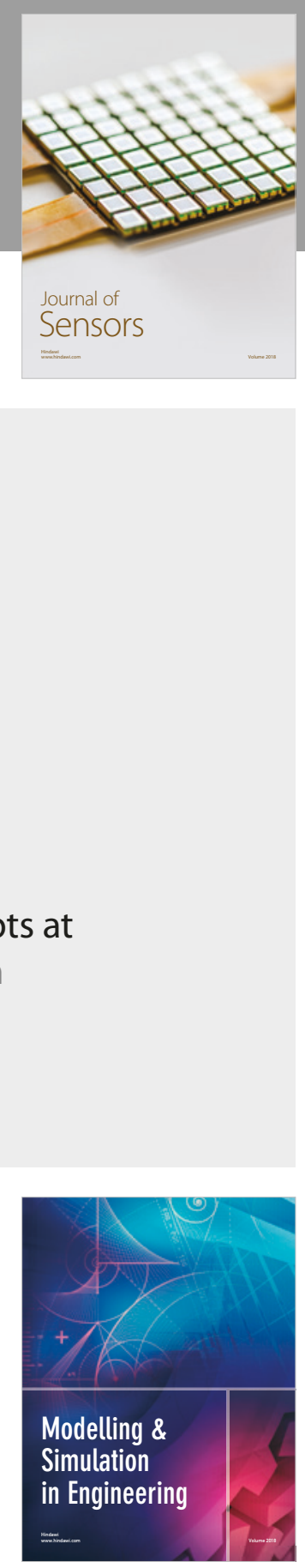

\section{Advances \\ Multimedia}
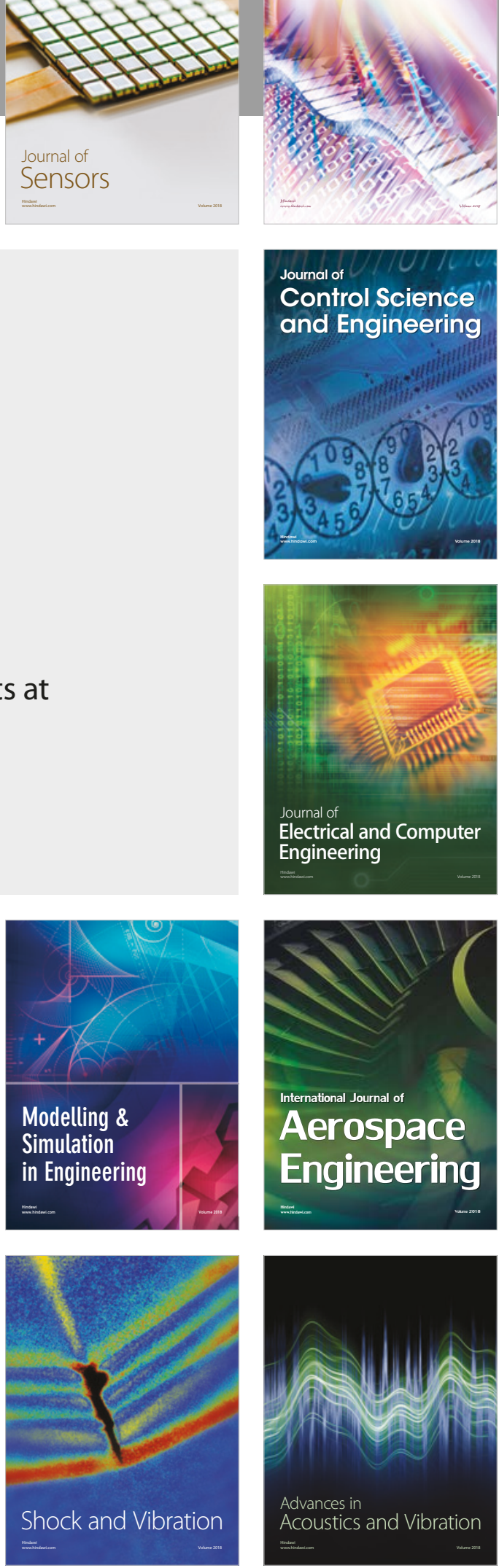